\title{
Article \\ Relationships of Gut Microbiota Composition, Short-Chain Fatty Acids and Polyamines with the Pathological Response to Neoadjuvant Radiochemotherapy in Colorectal Cancer Patients
}

\author{
Lidia Sánchez-Alcoholado ${ }^{1}$, Aurora Laborda-Illanes ${ }^{1}$, Ana Otero ${ }^{2}$, Rafael Ordóñez ${ }^{2}$, \\ Alicia González-González ${ }^{1}$ (D) , Isaac Plaza-Andrades ${ }^{1}$, Bruno Ramos-Molina ${ }^{3} \mathbb{D}$, Jaime Gómez-Millán ${ }^{2, *} \mathbb{D}$ \\ and María Isabel Queipo-Ortuño ${ }^{1, * \mathbb{D}}$
}

1 Unidad de Gestión Clínica Intercentros de Oncología Médica, Hospitales Universitarios Regional y Virgen de la Victoria, Instituto de Investigación Biomédica de Málaga (IBIMA)-CIMES-UMA, 29010 Málaga, Spain; 1.s.alcoholado@gmail.com (L.S.-A.); auroralabordaillanes@gmail.com (A.L.-I.); agonzalez.bq@gmail.com (A.G.-G.); isaacplazaandrade@gmail.com (I.P.-A.)

2 Unidad de Gestión Clínica de Oncología Radioterápica, Hospital Universitario Virgen de la Victoria, 29010 Málaga, Spain; ana.otero.rom@gmail.com (A.O.); rafaelordm@gmail.com (R.O.)

3 Grupo de Obesidad y Metabolismo, Instituto Murciano de Investigación Biosanitaria (IMIB-Arrixaca), 30120 Murcia, Spain; brunoramosmolina@gmail.com

check for

updates

Citation: Sánchez-Alcoholado, L.; Laborda-Illanes, A.; Otero, A.; Ordóñez, R.; González-González, A.; Plaza-Andrades, I.; Ramos-Molina, B.; Gómez-Millán, J.; Queipo-Ortuño, M.I. Relationships of Gut Microbiota Composition, Short-Chain Fatty Acids and Polyamines with the Pathological Response to

Neoadjuvant Radiochemotherapy in Colorectal Cancer Patients. Int. J. Mol. Sci. 2021, 22, 9549. https://doi.org/ 10.3390/ijms22179549

Academic Editors: Rustam I. Aminov and Catalina Carrasco-Pozo

Received: 18 August 2021

Accepted: 30 August 2021

Published: 2 September 2021

Publisher's Note: MDPI stays neutral with regard to jurisdictional claims in published maps and institutional affiliations.

Copyright: (c) 2021 by the authors. Licensee MDPI, Basel, Switzerland. This article is an open access article distributed under the terms and conditions of the Creative Commons Attribution (CC BY) license (https:/ / creativecommons.org/licenses/by/ $4.0 /)$.
* Correspondence: jaime.gomez@ibima.eu (J.G.-M.); maribel.queipo@ibima.eu (M.I.Q.-O.)

\begin{abstract}
Emerging evidence has suggested that dysbiosis of the gut microbiota may influence the drug efficacy of colorectal cancer (CRC) patients during cancer treatment by modulating drug metabolism and the host immune response. Moreover, gut microbiota can produce metabolites that may influence tumor proliferation and therapy responsiveness. In this study we have investigated the potential contribution of the gut microbiota and microbial-derived metabolites such as short chain fatty acids and polyamines to neoadjuvant radiochemotherapy (RCT) outcome in CRC patients. First, we established a profile for healthy gut microbiota by comparing the microbial diversity and composition between CRC patients and healthy controls. Second, our metagenomic analysis revealed that the gut microbiota composition of CRC patients was relatively stable over treatment time with neoadjuvant RCT. Nevertheless, treated patients who achieved clinical benefits from RTC (responders, $\mathrm{R}$ ) had significantly higher microbial diversity and richness compared to non-responder patients (NR). Importantly, the fecal microbiota of the $\mathrm{R}$ was enriched in butyrate-producing bacteria and had significantly higher levels of acetic, butyric, isobutyric, and hexanoic acids than NR. In addition, NR patients exhibited higher serum levels of spermine and acetyl polyamines (oncometabolites related to $\mathrm{CRC}$ ) as well as zonulin (gut permeability marker), and their gut microbiota was abundant in pro-inflammatory species. Finally, we identified a baseline consortium of five bacterial species that could potentially predict CRC treatment outcome. Overall, our results suggest that the gut microbiota may have an important role in the response to cancer therapies in CRC patients.
\end{abstract}

Keywords: colorectal cancer; gut microbiota; SCFAs; gut permeability; radiochemotherapy; treatment outcome

\section{Introduction}

Colorectal cancer (CRC) is the second most common malignant cancer in Western countries. The global burden of CRC is expected to substantially increase in the next two decades as a consequence of adopting Western lifestyles [1]. In recent years, several works have demonstrated that the gut microbiome could be a critical environmental factor that contributes to the tumorigenesis and progression of CRC, potentially by inducing pro-inflammatory responses, by producing microbial oncometabolites, and by interfering with the energy balance in cancer cells. Moreover, CRC is frequently associated with a dysbiosis in the microbial composition of the tumor and adjacent mucosa [2-4]. Several 
studies have suggested that the composition of the gut microbiota could affect the body's response to a variety of cancer therapies, including chemotherapy, radiotherapy, and immunotherapy [5-7].

Preoperative radiochemotherapy (RCT) followed by surgery has become the standard treatment for patients with CRC $[8,9]$. Recent studies have suggested that the gut microbiota may influence drug response (efficacy and toxicity) in CRC patients through several mechanisms such as immunomodulation, reduced diversity, translocation, metabolism, and ecological variation [10]. Specific gut bacteria have been shown to affect cancer treatment by modulating drug metabolism and the host immune response [11,12]. Thus, several phyla are known to mediate drug metabolism via different reactions such as isoxazole scission, denitration, proteolytic degradation, acetylation/deacetylation, deconjugation, physical adherence to the drugs as well as by amine formation and/or hydrolysis [13]. Scott et al. described that the gut microbiota was able to influence the efficacy of one of the first-line treatments for CRC, such asfluoropyrimidines, through drug interconversion involving bacterial vitamin B6 and B9 and ribonucleotide metabolism [14]. In addition, the effect 5-fluorouracil treatment in CRC cells could be mediated by gut microbial metabolites [15]. Remarkably, Fusobacterium nucleatum is able to promote CRC resistance to chemotherapy by targeting both TLR4 and MYD88 innate immune signaling [16]. Furthermore, radiation may also lead to alterations in gut microbiota composition in animal models [17]. However, the clinical impact of radiotherapy on gut microbiota in cancer patients remains mostly unexplored although it has been proposed that the gut microbiota might play a role in the immunogenic effect of radiotherapy [18].

On the other hand, the gut microbiome produces bacteria-derived metabolites that could affect cancer proliferation and chemotherapy responsiveness. Thus, previous studies describe that SCFAs (such as butyric acid, isobutyric acid and acetic acid) inhibit the growth of cultured human colorectal cancer cells and that butyric acid is the strongest inhibitor [19]. Ross et al. reported an association between the levels of the short-chain fatty acids (SCFAs) propionate and butyrate in patients with early stage breast cancer with a pathological complete response (pCR) to neoadjuvant chemotherapy [20]. Coutzac et al. suggested that SCFA limits anti-CTLA-4 activity in patients with metastatic melanoma [21].

In addition, lower SCFA (especially butyrate) concentrations might induce a dysfunction in the gut epithelial barrier, thereby activating proinflammatory cytokines such as interleukin-6 (IL-6) and tumor necrosis factor- $\alpha$ (TNF- $\alpha$ ), which damage epithelial cells and their junctions [22].

Other bacteria-derived metabolites, such as the polyamines (PAs) (spermine, spermidine and putrescine), have been involved in almost all the steps of colorectal tumorigenesis. PAs are molecules that are indispensable in normal cell growth and gene expression and are needed in cell proliferation, but their concentrations increase during the transition from a healthy cell to a tumor cell [23]. Recently, it was shown that the level of acetylated PAs is more specific for cancer. For example, N1, N12-diacetylspermine (DiAcSPM) was increased in CRC and in dysplastic colorectal lesions [24].

Therefore, taking all of the evidence together, we hypothesized a bidirectional interaction between the neoadjuvant RCT and the gut microbiome in CRC patients: RCT might induce alterations in the gut microbiome, and these alterations might, in turn, influence the effectiveness of RCT by directly interacting with the treatment and/or by stimulating the host's immune response.

In this study, we aimed to identify the possible relationship between the gut microbiome, the fecal SCFAs levels, the serum levels of the polyamines and acetyl derivatives of polyamines, and the intestinal permeability to neoadjuvant RCT outcome in CRC patients.

\section{Results}

\subsection{Clinical Characteristics of the Patients and Healthy Controls}

CRC patients and healthy controls had comparable eating habits to exclude the influence of dietary differences. CRC patients and healthy controls followed a Mediterranean 
diet consisting in a high consumption of olive oil, fruits, legumes, vegetables, nuts, whole grains, and fish and a low intake of red meat and dairy products. Adherence to the Mediterranean diet was assessed by using a validated 14-item food frequency questionnaire in all study patients. All CRC patients completed the neoadjuvant RCT and underwent surgical resection. There was no significant difference between CRC patients and healthy controls in terms of age, sex, BMI, and biochemical data (Table 1). A total of 28 of the 40 CRC patients $(70 \%)$ had a good response to the neoadjuvant RCT (responders, R) (TGR 1-2), and $12(30 \%)$ had a poor or non-response (non-responders, NR) (TGR 3-5) to therapy. Both R and NR patients were similar in terms of sex, age, BMI, and stage of the cancer, as shown in Table 1.

Table 1. Clinical characteristics of study groups.

\begin{tabular}{|c|c|c|c|c|c|c|}
\hline & $\begin{array}{l}\text { Healthy } \\
\text { Controls } \\
(\mathrm{N}=20)\end{array}$ & $\begin{array}{l}\text { CRC-Patients } \\
\quad(\mathrm{N}=40)\end{array}$ & $* p$ & $\begin{array}{c}\text { R Patients } \\
(\mathrm{N}=\mathbf{2 8})\end{array}$ & $\begin{array}{l}\text { NR Patients } \\
\quad(\mathrm{N}=12)\end{array}$ & $* p$ \\
\hline Age (years) & $61.42 \pm 7.40$ & $63.35 \pm 6.97$ & 0.326 & $62.93 \pm 8.27$ & $63.12 \pm 6.34$ & 0.928 \\
\hline Gender, n (M/F) & $10 / 10$ & $23 / 17$ & 0.783 & $16 / 12$ & $7 / 5$ & 0.780 \\
\hline $\mathrm{BMI}\left(\mathrm{kg} / \mathrm{m}^{2}\right)$ & $25.45 \pm 3.23$ & $26.42 \pm 4.71$ & 0.412 & $26.22 \pm 4.22$ & $25.92 \pm 3.92$ & 0.835 \\
\hline Constipation, n (\%) & $6(20 \%)$ & $10(25 \%)$ & 0.914 & $7(25 \%)$ & $3(25 \%)$ & 0.690 \\
\hline $\begin{array}{l}\text { Alcohol consumption, } \\
\mathrm{n}(\%)\end{array}$ & $4(13.3 \%)$ & $6(15 \%)$ & 0.831 & $4(14.28 \%)$ & $2(16.16 \%)$ & 0.740 \\
\hline $\begin{array}{l}\text { Current smoking, n (\%) } \\
\text { Biochemical data }\end{array}$ & $9(30 \%)$ & $15(37.5 \%)$ & 0.774 & $11(39.28 \%)$ & $4(33.33 \%)$ & 0.990 \\
\hline Glucose (mg/dl) & $94.85 \pm 19.86$ & $104.79 \pm 27.94$ & 0.161 & $102.83 \pm 26.38$ & $104.15 \pm 23.56$ & 0.882 \\
\hline Total cholesterol (mg/dl) & $175.2 \pm 33.6$ & $183.95 \pm 25.71$ & 0.268 & $184.17 \pm 21.64$ & $181.67 \pm 26.12$ & 0.755 \\
\hline Triglycerides (mg/dl) & $112.67 \pm 34.51$ & $114.85 \pm 33.62$ & 0.815 & $109.25 \pm 32.12$ & $118.32 \pm 27.12$ & 0.398 \\
\hline HDL-cholesterol (mg/dl) & $60.7 \pm 15.1$ & $54.83 \pm 18.23$ & 0.219 & $55.32 \pm 16.21$ & $53.89 \pm 18.34$ & 0.807 \\
\hline LDL-cholesterol (mg/dl) & $107.78 \pm 27.12$ & $112.07 \pm 33.45$ & 0.621 & $109.68 \pm 30.29$ & $112.36 \pm 33.21$ & 0.805 \\
\hline \multicolumn{6}{|l|}{ Histological variables } & \\
\hline II & & $22(55 \%)$ & - & $15(53.57 \%)$ & $7(58.33 \%)$ & 0.945 \\
\hline III & & $18(45 \%)$ & - & $13(46.42 \%)$ & $5(41.66 \%)$ & 0.950 \\
\hline \multicolumn{7}{|l|}{$\begin{array}{l}\text { Tumor depth } \\
\text { penetration }(\mathrm{T})\end{array}$} \\
\hline $\mathrm{T} 2-\mathrm{T} 3$ & & $26(65 \%)$ & - & $18(64.28 \%)$ & $8(66.66 \%)$ & 0.828 \\
\hline $\mathrm{T} 4$ & & $14(35 \%)$ & - & $10(35.71 \%)$ & $4(33.33 \%)$ & 0.832 \\
\hline \multicolumn{7}{|l|}{ Grade of differentiation } \\
\hline G1 & & $18(45 \%)$ & - & $12(42.85 \%)$ & $6(50 \%)$ & 0.944 \\
\hline G2 & & $10(25 \%)$ & - & $7(25 \%)$ & $3(25 \%)$ & 0.690 \\
\hline G3 & & $7(17.5 \%)$ & - & $5(18.85 \%)$ & $2(16.16 \%)$ & 0.806 \\
\hline No differentiation & & $5(12.5 \%)$ & - & $3(10.71 \%)$ & $2(16.66 \%)$ & 0.777 \\
\hline
\end{tabular}

CRC: colorectal cancer; R: responders; NR: non-responders; BMI: body mass index; HDL: high density lipoprotein; LDL: low density lipoprotein. Values are expressed as mean $\pm \mathrm{SD}$. ${ }^{*} p<0.05$ was considered statistically significant.

\subsection{Differences in Taxonomic Composition and Diversity of Gut Microbiota between CRC Patients and Healthy Controls}

The analysis of stool samples revealed 17,496,823 reads of the $16 \mathrm{~S}$ rRNA gene (hypervariable V2-V9 regions), with an average of $105,632( \pm 10,825)$ reads for each sample in a range between 359 and 39,873. After trimming and filtering, 52,844 high-quality reads were selected. A total of 15,326 OTUs were obtained in the OTUs clustering process, and after the alignment of the OTU representative sequences, 2582 OTUs were identified to have a relative abundance $>1 \%$ in at least four samples ( $97 \%$ similarity cut-off). For the taxonomic assignment of these OTUs, QIIME2 pipeline and Greengenes v13.8 were used, and the OTUs were binned into 7 phyla, 39 families, 45 genera, and 53 species.

We first compared the landscape of the gut microbiome in the stool samples of all CRC patients at baseline and in healthy controls in order to define a normal gut microbiota profile. As expected, we found significantly higher diversity and richness (defined by the Shannon and Chao1 indexes, respectively) in the fecal samples of healthy controls with 
respect to those of CRC patients (Shannon $p=0.026$ and Chao1 $p=0.001$ ) (Figure S1A,B). The beta diversity (Bray-Curtis dissimilarity) comparison of the baseline CRC patients and the healthy controls indicated that the two cohorts had significantly different genus compositions of intestinal bacteria ( $p=0.0001$, ANOSIM) (Figure S1C).

Furthermore, the analysis of the gut microbiota profiles between the CRC patients and the healthy controls at baseline revealed significant differences in the abundance at different taxonomic levels. At phylum level, the relative abundance of Fusobacteria $(\mathrm{q}<0.001)$, Firmicutes $(q<0.001)$, Lentisphaerae $(q=0.007)$, and Proteobacteria $(q=0.003)$ were significantly increased in patients with $C R C$, while the relative abundance of Bacteroidetes $(\mathrm{q}<0.001)$ and Actinobacteria $(\mathrm{q}=0.034)$ were significantly decreased in CRC patients when compared to the controls (Figure 1A).

At the genus level, the results indicated significant differences in the microbial composition of the dominant genera between the CRC patients at baseline and the healthy controls. Compared to the healthy controls, patients with CRC displayed an enrichment in the genera Prevotella $(\mathrm{q}<0.001)$, Oscillospira $(\mathrm{q}<0.001)$, Fusobacterium $(\mathrm{q}=0.001)$, Enter$\operatorname{obacter}(\mathrm{q}=0.020)$, Victivallis $(\mathrm{q}=0.012)$, Escherichia $(\mathrm{q}=0.046)$, and Desulfovibrio $(\mathrm{q}<0.001)$. Conversely, the abundance of Bacteroides $(\mathrm{q}=0.003)$, Roseburia $(\mathrm{q}<0.001)$, Ruminococcus $(\mathrm{q}=0.006)$, Faecalibacterium $(\mathrm{q}=0.01)$, Bifidobacterium $(\mathrm{q}=0.023)$, and Blautia $(\mathrm{q}=0.014)$ were enriched in the healthy controls compared to in the CRC patients (Figure 1B).

At species level, while healthy subjects showed a significantly higher abundance of Bifidobacterium bifidum $(\mathrm{q}=0.034)$ and Faecalibacterium prausnitzii $(\mathrm{q}=0.040)$ with respect to the CRC patients, Fusobacterium nucleatum $(\mathrm{q}=0.020)$, Bacteroides fragilis $(\mathrm{q}=0.024)$, and Escherichia coli $(\mathrm{q}=0.016)$ were significantly increased in the fecal samples of CRC patients in comparison to the controls.

\subsection{Changes in Gut Microbiota Diversity and Composition in Response to Neoadjuvant RCT Treatment in CRC Patients}

We compared the gut microbiota communities at baseline (T0) versus at post-treatment time points (T1, T2, and T3) to study the effect of neoadjuvant RCT on the gut microbial diversity and composition in CRC patients. The alpha diversity comparison showed no significant differences in the levels of richness (Chao 1) and diversity (Shannon) between the baseline and the different time points (Shannon $p=0.75$ and Chao1 $p=0.61$ ) (Figure 2A,B). Moreover, the PCoA plot based on the beta diversity (Bray-Curtis dissimilarity) revealed that the differences in the gut microbial community at T1, T2, and T3 compared to at baseline (T0) were not significant ( $p=0.716$, ANOSIM) (Figure 2C).

The main bacterial phyla (Firmicutes and Bacteroidetes) remained stable over time, while other, less abundant phyla, such as Fusobacteria and Proteobacteria, were significantly decreased at $\mathrm{T} 3$ compared to at $\mathrm{T} 0(\mathrm{q}=0.042$ and $\mathrm{q}=0.039$, respectively) in the CRC patients. Although the bacterial family and genera proportions differed between the different time points, they were not significantly altered by the RCT treatment (Wilcoxon test $p>0.05)$, apart from the genera Fusobacterium $(\mathrm{q}=0.015)$, Escherichia $(\mathrm{q}=0.04)$ and Klebsiella $(\mathrm{q}=0.035)$, which were significantly decreased after treatment, and the genus Bifidobacterium $(q=0.049)$, which was significantly increased at T3 compared to T0 (Figure 3).

\subsection{Post-Treatment Microbiota Diversity and Composition Is Associated to Clinical Response to} Neoadjuvant RCT in CRC Patients

To evaluate the relationship between the microbial community and the treatment outcome, we classified the patients based on their response to RCT into categories such as responders (R) and non-responders (NR). As shown in Table 1, no significant differences in terms of stage of cancer, sex, age, and BMI were observed between the study groups (R vs. NR). 
(A)

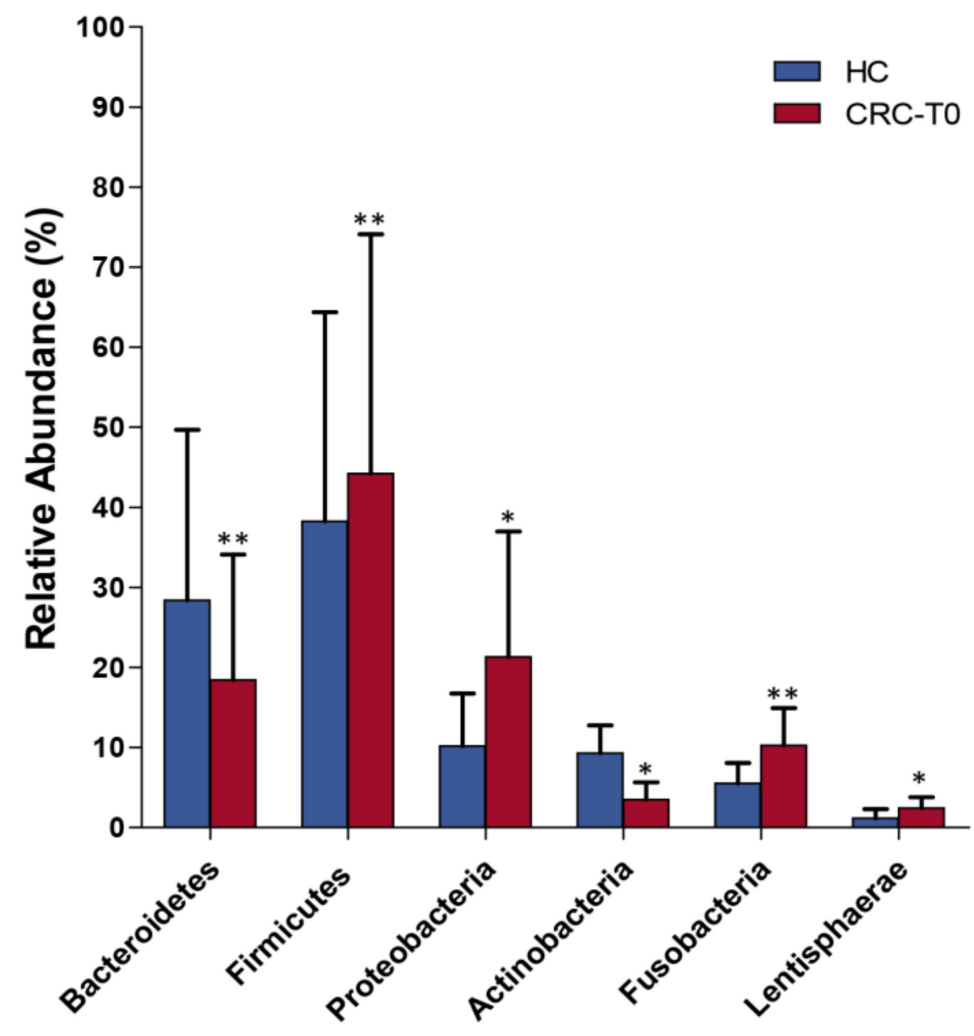

(B)

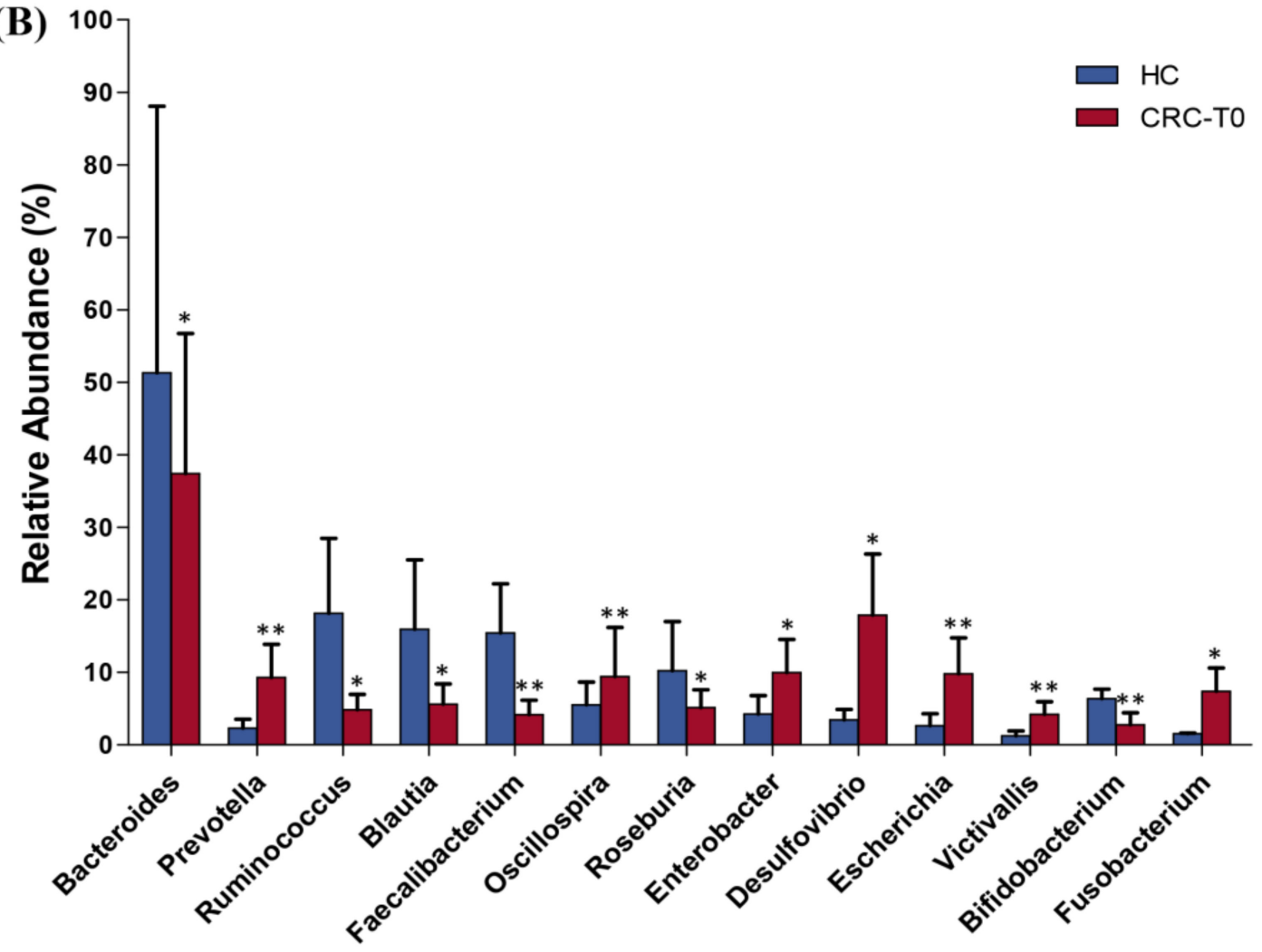

Figure 1. Relative abundance at phylum (A) and genera (B) levels of differentially abundant bacteria in the stool samples of CRC patients at baseline (CRC-T0) and healthy controls (HC). ${ }^{*} p<0.05,{ }^{* *} p<0.001$. 

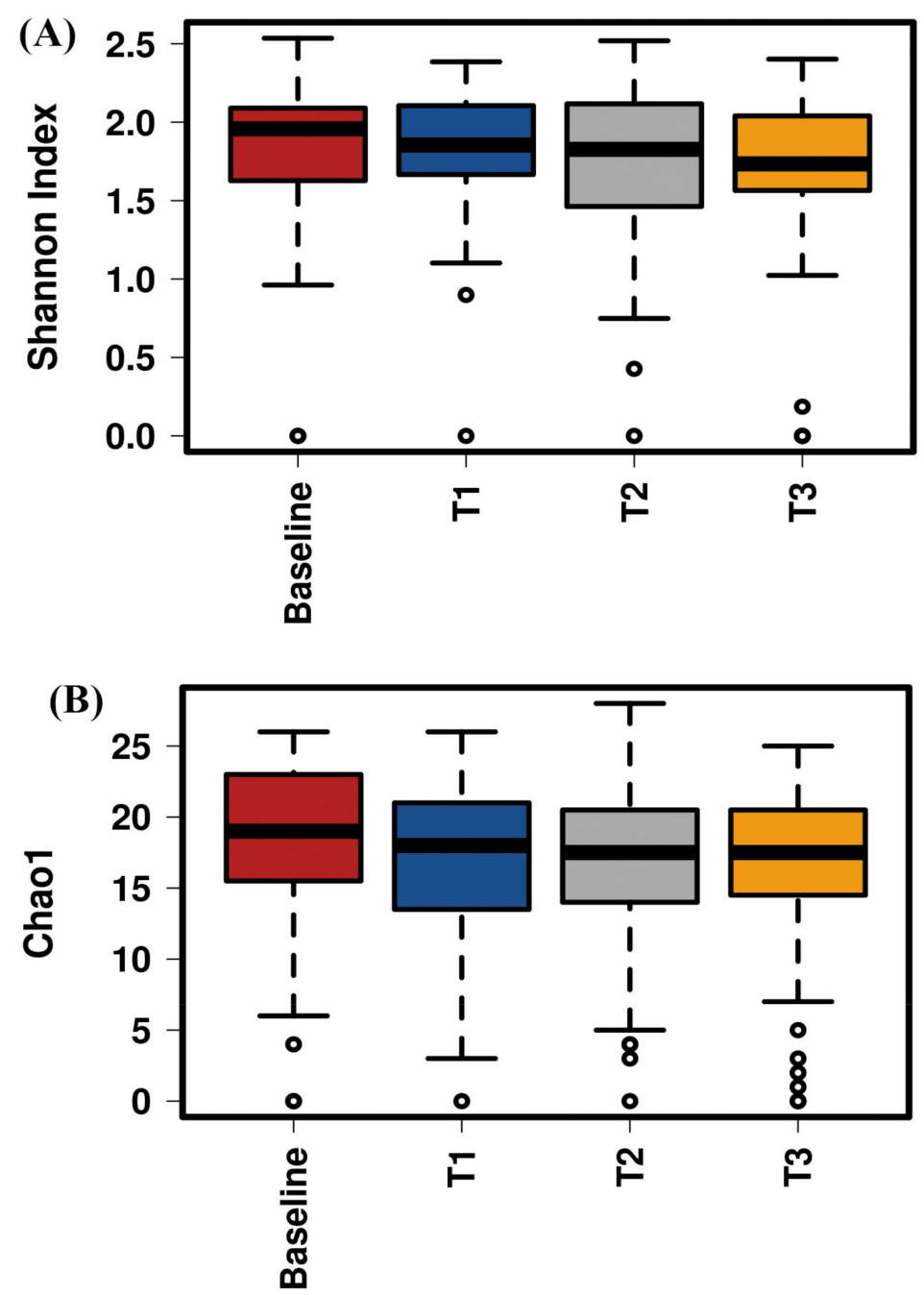

(C)

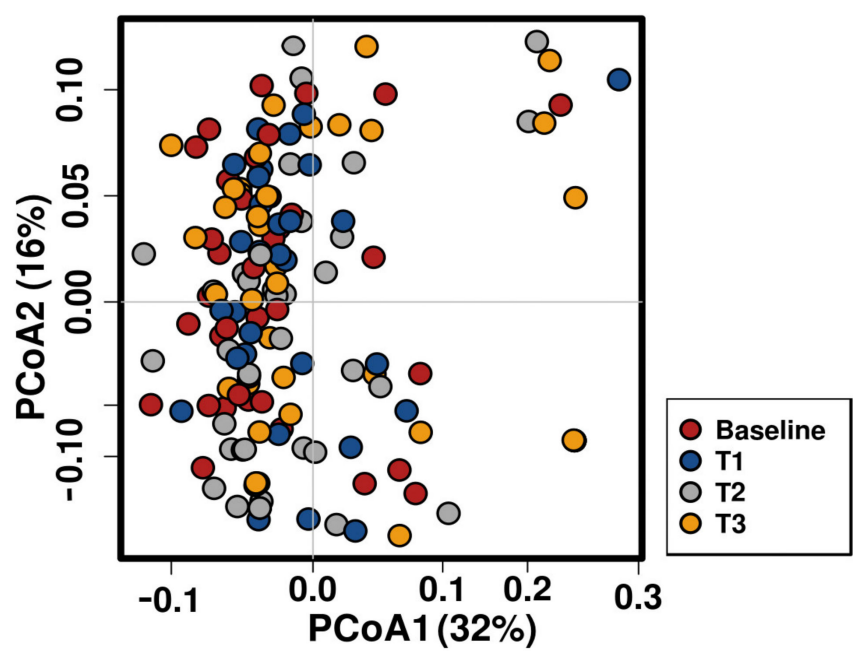

Figure 2. Gut microbiota diversity and richness at baseline and during RTC treatment and posttreatment points in CRC patients. (A) Shannon index $(p=0.75)$; (B) Chao1 index $(p=0.61)$; (C) principal component analysis representation based on Bray-Curtis distance matrix of patient distribution based on bacterial genera composition at baseline and during RTC treatment and at post-treatment points $(p=0.716)$. The first two coordinates are plotted with the percentage of variability, which is explained and indicated on the axis. 


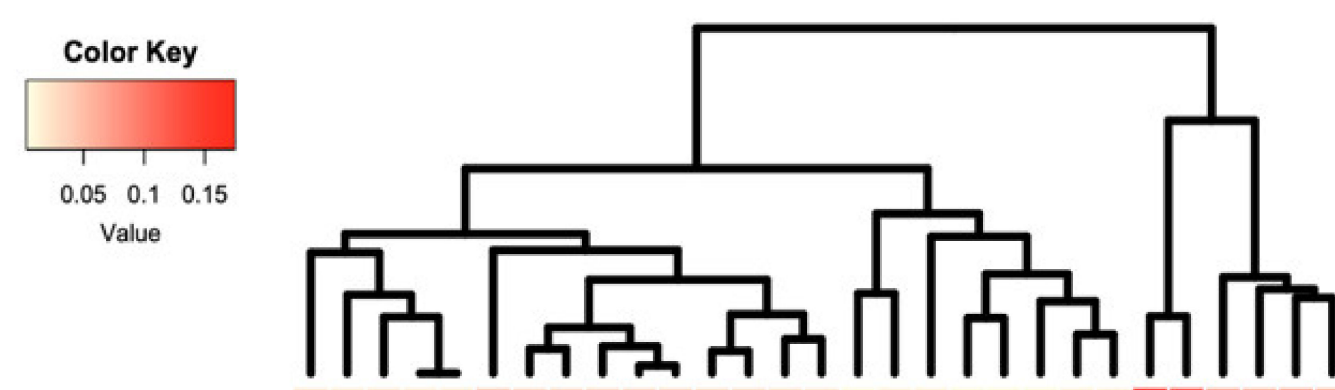

CRC-T2
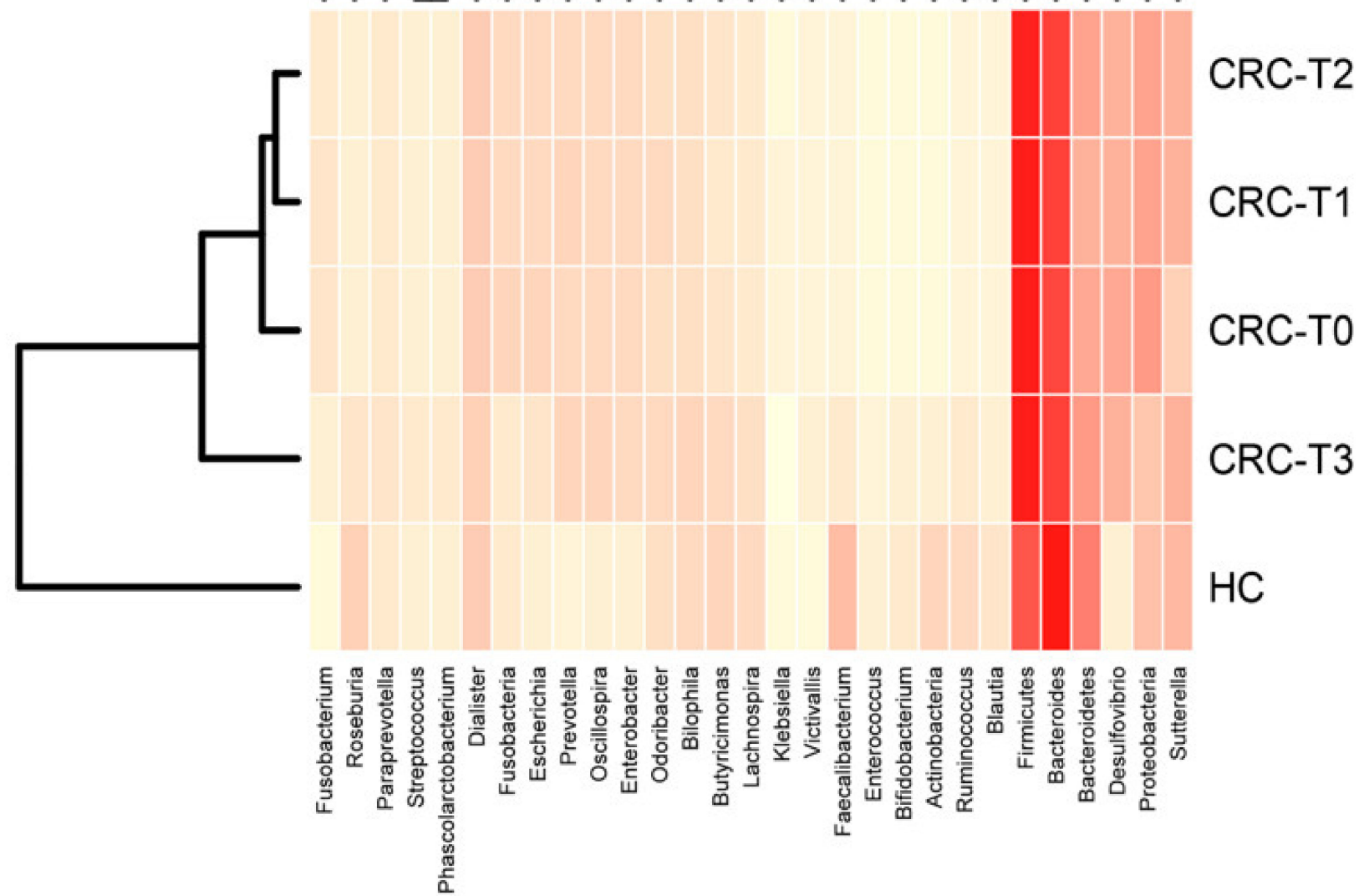

Figure 3. Heatmap diagram of the gut microbiota composition at different taxa levels for baseline (CRC-T0), treatment points with neoadjuvant RCT (CRC-T1, CRC-T2 and CRC-T3), and the healthy control subjects (HC). The 29 phylum and genera that were shared by all of the tested samples (core microbiome) are displayed.

An analysis of the alpha diversity at $\mathrm{T} 3$ revealed that the $\mathrm{R}$ group had higher diversity (Shannon index, $\mathrm{q}<0.001$; Simpson index, $\mathrm{q}=0.039$ ) and richness that the NR group (Chao1 index, $\mathrm{q}=0.015$ ) at genus level (Figure $4 \mathrm{~A}, \mathrm{~B}$ ). Furthermore, the ordination plot based on Bray-Curtis dissimilarities and the Jaccard index showed different intestinal microbial compositions at the genus level between both the $\mathrm{R}$ and the NR groups at T3 (Bray-Curtis index, $\mathrm{q}=0.038$; Jaccard index, $\mathrm{q}=0.035$; non-parametric ANOSIM test) (Figure 4C).

Next, we searched for differentially abundant taxa in the gut microbiome of $R$ versus $\mathrm{NR}$ at T3. The analysis revealed that at the phylum level, there was a significant enrichment in the Actinobacteria $(q=0.0025)$ and Firmicutes $(q=0.0017)$ populations and a significant decrease in the Fusobacterias $(q=0.025)$ and Proteobacterias $(q=0.037)$ populations in the $\mathrm{R}$ group in comparison to the NR group (Figure $5 \mathrm{~A}, \mathrm{~B}$ ). At the family level, a significantly higher abundance of Ruminococcaceae $(q=0.004)$ and Bifidobacteriaceae $(q=0.03)$ accompanied with a significantly lower abundance of Prevotellaceae $(q=0.045)$, Enterobactericeae $(q=0.027)$, and Fusobacteriaceae $(q=0.014)$ were shown in the R group compared to in the NR group (Figure 5A,C). 
(A)

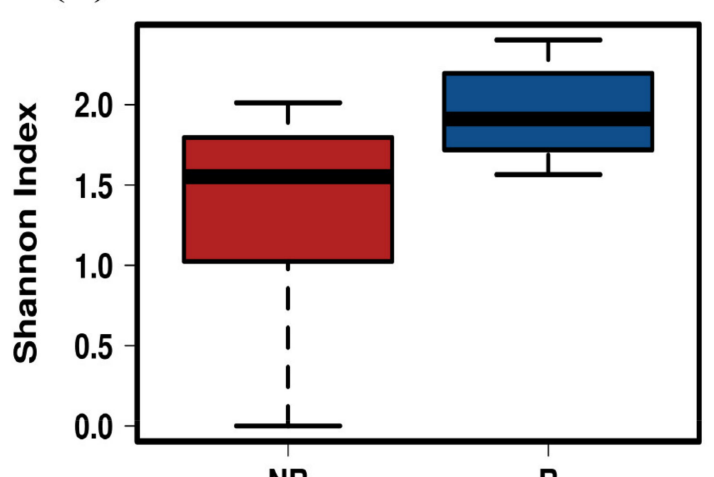

NR

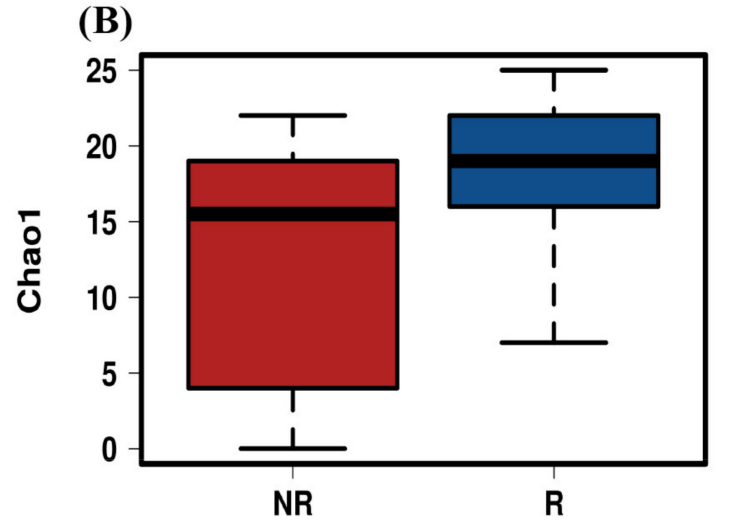

(C)

PCoA Bray-Curtis

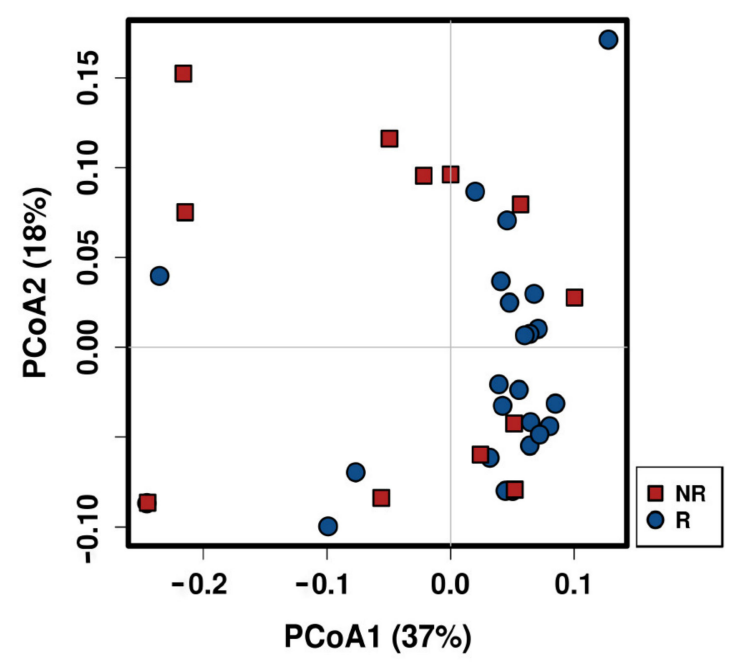

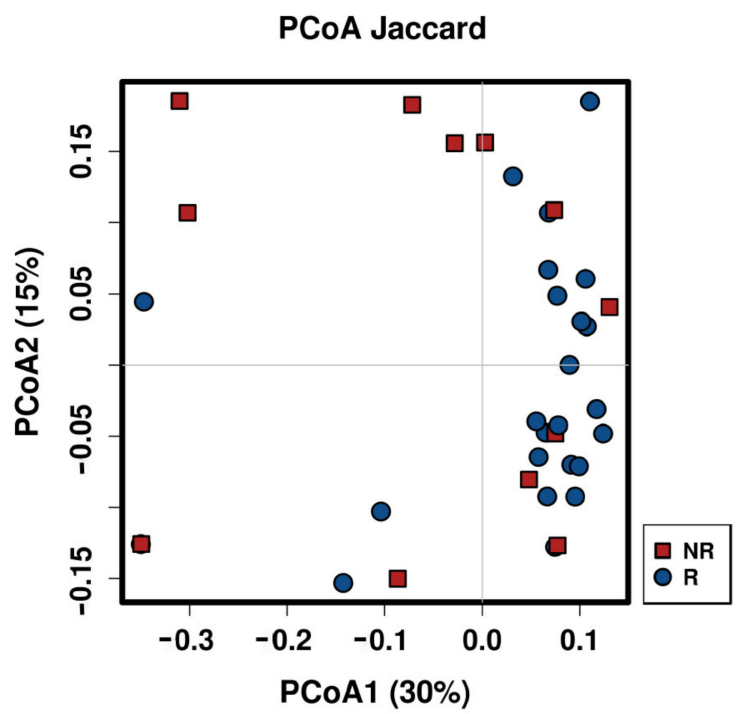

Figure 4. Comparison of alpha and beta diversity in CRC patients according to their response to therapy. (A) Shannon index; (B) Chaolindex; (C) principal component plot based on the Bray-Curtis distance matrix and the Jaccard indices from the responder $(\mathrm{R})$ and non-responder (NR) patients at genus-level. The first two coordinates are plotted with the percentage of variability, which is explained and indicated on the axis.

In addition, at the genera level, we identified a significant increase in Ruminococcus $(q=0.035)$, Bilophila $(q=0.008)$, Collinsiella $(q=0.015)$, Bifidobacterium $(q=0.024)$, Roseburia $(q=0.032)$, and Faecalibacterium $(q=0.041)$ in $R$ patients with respect to the $N R$, while a significant increase in Prevotella $(q=0.05)$, Fusobacterium $(\mathrm{q}=0.045)$, Escherichia $(\mathrm{q}=0.037)$, Bacteroides $(q=0.027)$, and Klebsiella $(q=0.035)$ were observed in the NR patients compared to the R group (Figure 6A,B). Finally, at the species level, we found a significant overabundance of Prevotella copri $(q<0.001)$, Escherichia coli $(q=0.029)$, Fusobacterium nucleatum $(q=0.015)$, and Bacteroides fragilis $(q=0.029)$ in the NR group, while the R group displayed a significantly higher abundance of Bifidobacterium bifidum $(\mathrm{q}=0.043)$, Ruminococcus albus $(q=0.019)$, Collinsella aerofaciens $(q=0.018)$, and Faecalibacterium prausnitzii $(q=0.027)$.

\subsection{Baseline Microbiota Composition Could Predict Response to RCT Treatment in CRC Patients}

After describing the significant differences in the intestinal microbial composition between the R and NR after RCT treatment, we next assessed the predictive power of the gut microbiome related to neoadjuvant RCT response. We used random forest (RF) to build a predictive model based on the overall gut microbiota profile using the species-level abundance data as input. After RF analysis with 500 bootstrap samples, we found that 
the overall gut microbiota composition data had a significant accuracy of $80 \%$ and an area under the curve (AUC) of 0.71. The main species accounting for this stratification were Ruminococcus albus, Bifidobacterium bifidum, Faecalibacterium prausnitzii, Fusobacterium nucleatum, and Bacteroides fragilis, and when the proportions of these bacterial species were only used for testing the accuracy of the RF classifier, this increased to $96 \%$ (AUC $=0.92$ ). Thus, the response to RTC or the lack of it were identified with an accuracy of $94 \%$ $(\mathrm{AUC}=0.95)$ and of $91 \%(\mathrm{AUC}=0.92)$, respectively (Figure $7 \mathrm{~A})$. The validation cohort consisted of $84 \mathrm{CRC}$ patients under neoadjuvant RCT (45 R patients and $39 \mathrm{NR}$ patients) (data collected from the Genome Sequence Archive in National Genomics Data Center, accession number CRA002850). After RF analysis in this validation cohort, an accuracy of $92.0 \%$ (AUC $=0.93$ ) and $90.0 \%$ (AUC $=0.91$ ) were obtained for the response to RTC or the lack of it, respectively (Figure 7B). Among the five species variables, Fusobacterium nucleatum, and Bacteroides fragilis were biomarkers of $\mathrm{R}$ patients, and Ruminococcus albus, Bifidobacterium bifidum, and Faecalibacterium prausnitzii were biomarkers of NR patients.

(A)
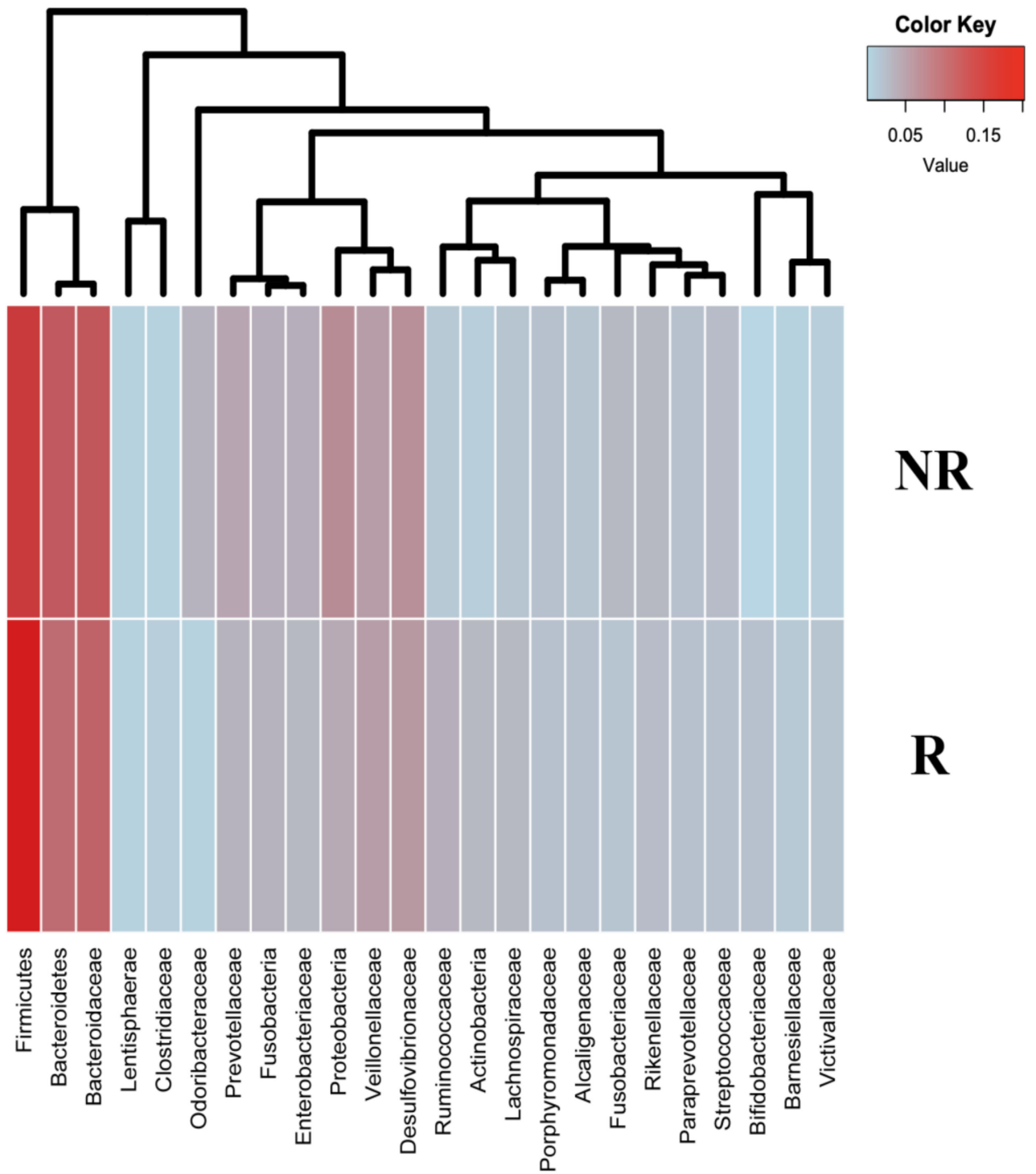

NR

$\mathbf{R}$

Figure 5. Cont. 
(B)

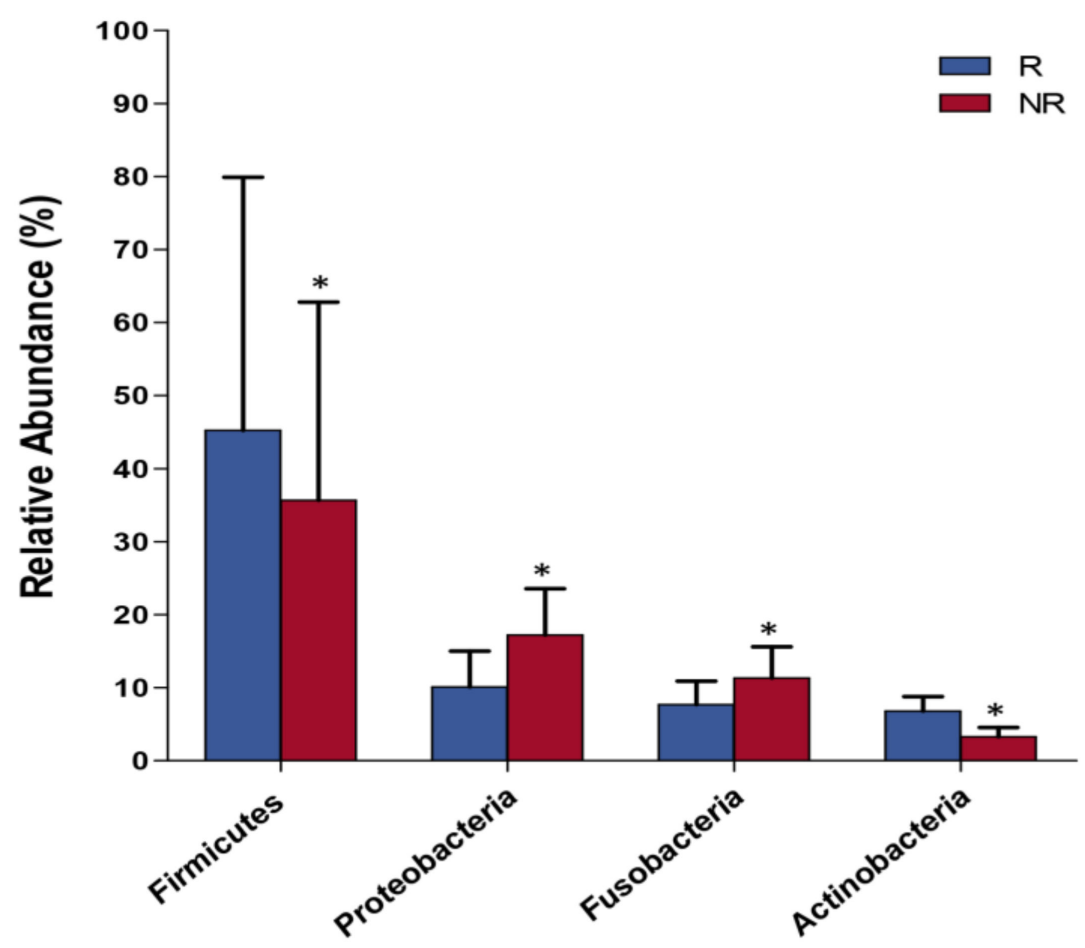

(C)

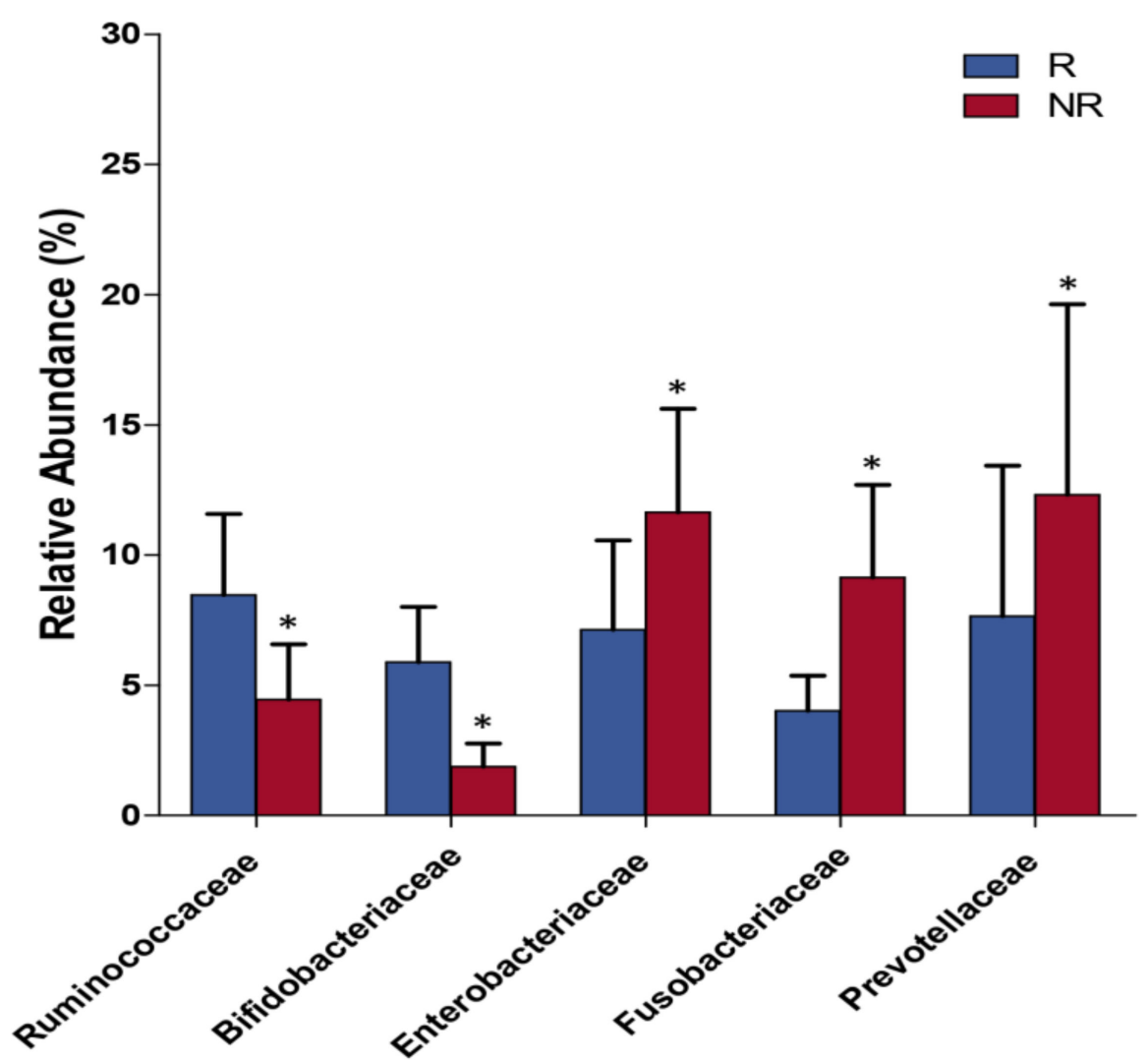

Figure 5. Heatmap of the fecal microbiota composition at the phylum and family levels in the responder (R) and nonresponder (NR) patients (A). Relative abundance at phylum (B) and family (C) levels of differentially abundant OTUs in the stool samples of $\mathrm{N}$ patients compared to the NR patients. ${ }^{*} p<0.05$. 
(A)
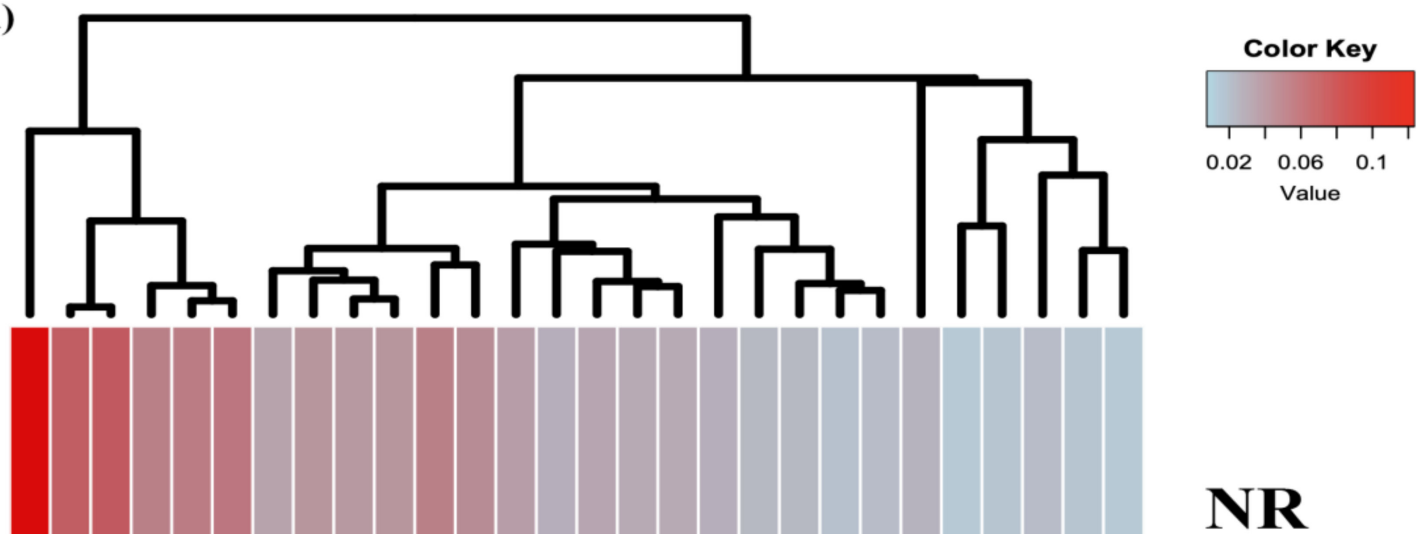

(B)

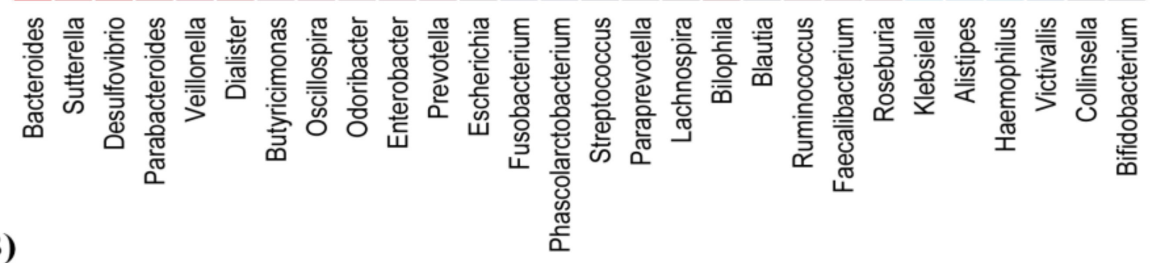

$\mathbf{R}$

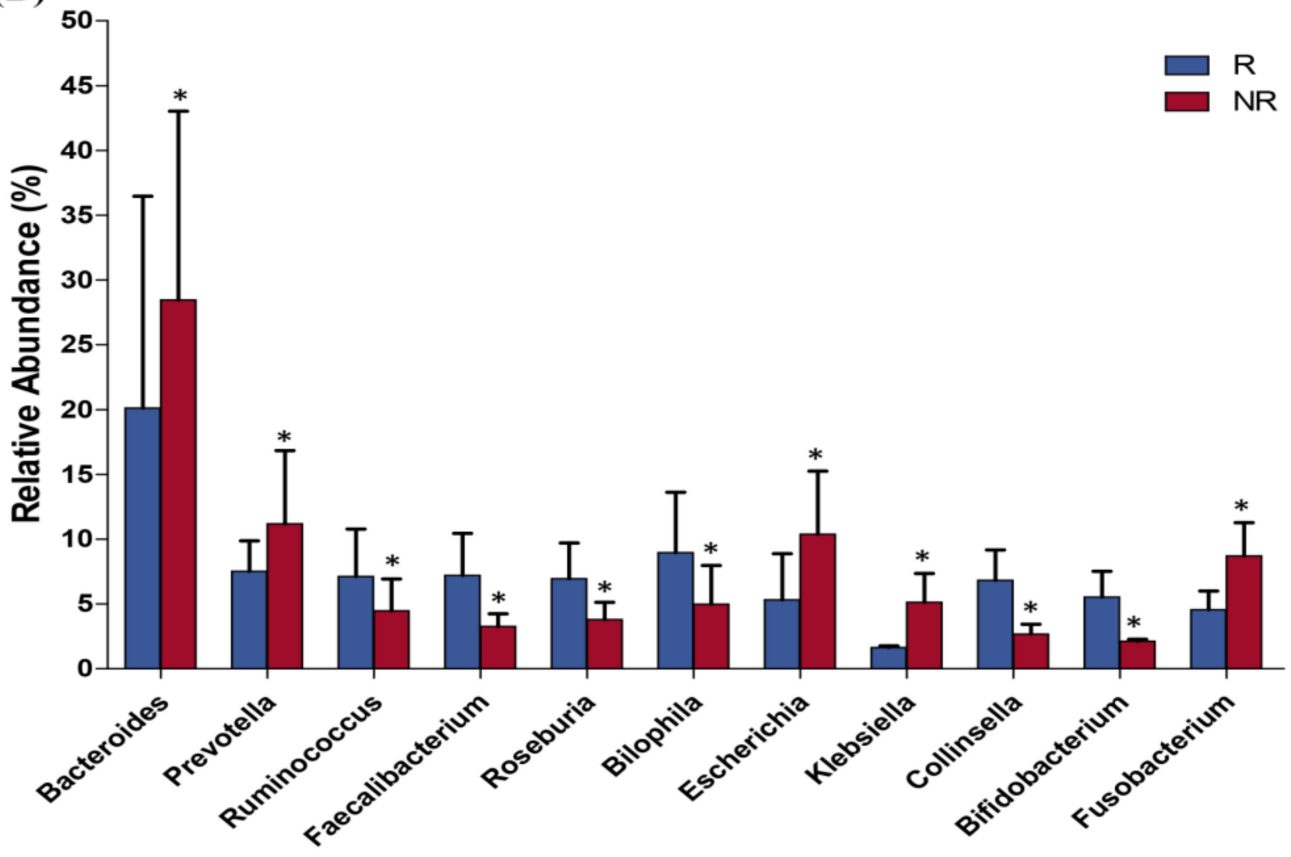

Figure 6. Heatmap of the fecal microbiota composition at genera level in the responder (R) and non-responder (NR) patients (A). Relative abundance at genera level of differentially abundant OTUs in the stool samples of the N patients compared to the NR patients. ${ }^{*} p<0.05(\mathbf{B})$. 
(A)

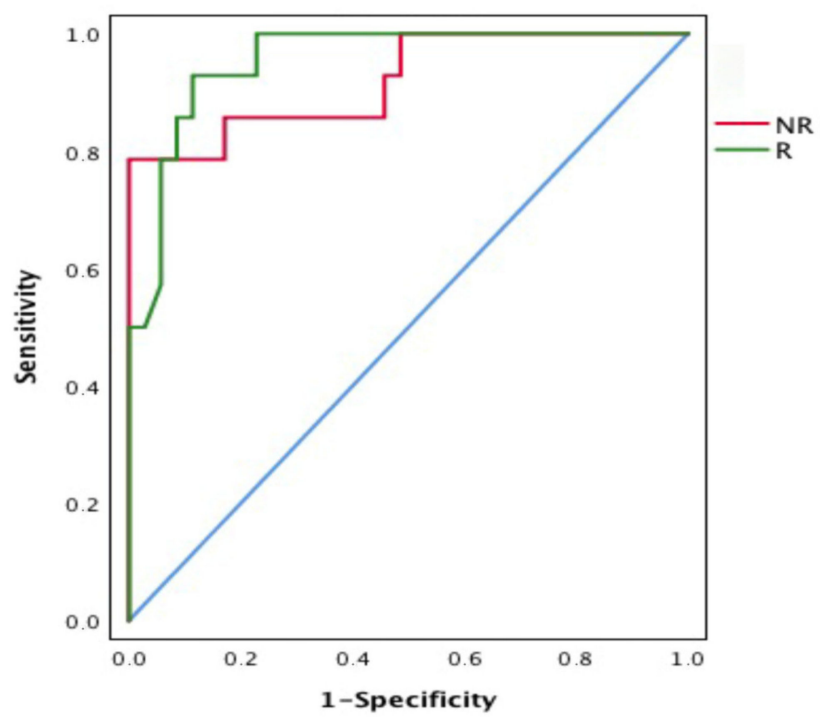

(B)

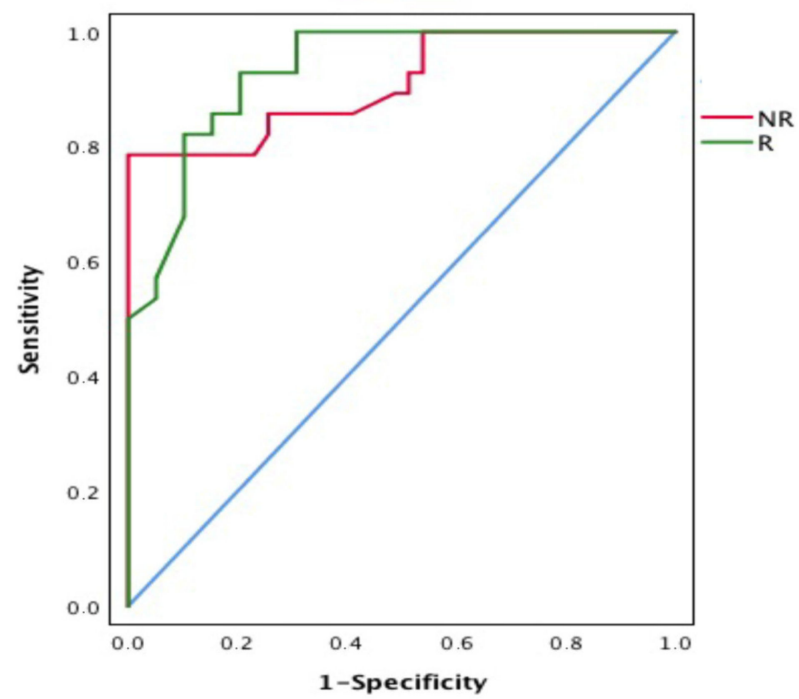

Figure 7. Receiver operating characteristic (ROC) curve based on the random forest classifier constructed using microbial variables (Ruminococcus albus, Bifidobacterium bifidum, Faecalibacterium prausnitzii, Fusobacterium nucleatum, and Bacteroides fragilis). (A) Training cohort. The area under the ROC curve (AUC) was 0.95 , and the $95 \%$ confidence interval (CI) was 0.901-1 for the R patients (green), and the AUG was 0.92 and $95 \%$ the IC was $0.827-1$ for the NR patients (red). (B) Validation cohort. The AUG was 0.93 and the $95 \%$ IC was $0.877-0.987$ for the R patients (green), and the AUG was 0.91 and $95 \%$ the IC was $0.835-0.984$ for the NR patients (red).

\subsection{Differences in the Gut Microbiota Functions between Responder and Non-Responder}

KEGG pathway enrichment analysis of the metagenomic data showed that genes for energy metabolism such as methane metabolism $(\mathrm{q}<0.004)$, carbohydrate metabolism, such as the pentose phosphate pathway $(\mathrm{q}=0.0022)$, pyruvate metabolism ( $\mathrm{q}$-value $<0.001$ ), starch and sucrose metabolism $(q=0.008)$, galactose metabolism $(q=0.007)$, butanoate metabolism ( $q=0.005)$, and glycolysis-gluconeogenesis ( $q=0.0028)$; for xenobiotic biodegradation and metabolism pathways, including benzoate degradation $(q=0.038)$ and nitrotoluene degradation $(\mathrm{q}=0.005)$; and membrane transport, such as $A B C$ transporters $(q=0.012)$ and transporters $(q=0.012)$, were significantly depleted in NR compared to $\mathrm{R}$ patients.

Nevertheless, compared to the R patients, in the NR patients, there was a significant over-representation of genes for lipid metabolism, such as for araquidonic acid metabolism ( $q=0.006)$; amino acid metabolism pathways, such as for arginine and proline metabolism ( $q=0.029)$; for glycine, serine, and threonine metabolism ( $q=0.001)$; in genes for the metabolism of other amino acids such as glutathione metabolism ( $q=0.003)$; for the metabolism of cofactors and vitamins such as riboflavin metabolism $(q=0.003)$, ubiquinone, and other terpenoid metabolism $(q<0.001)$; folate biosynthesis $(q=0.014)$, glycan biosynthesis, and metabolism, such as lipopolysaccharide biosynthesis ( $q=0.007)$; lipopolysaccharide biosynthesis proteins $(\mathrm{q}=0.001)$; cellular processes and signaling that contain cell motility and secretion $(\mathrm{q}=0.0018)$; oxidative phosphorylation $(\mathrm{q}<0.001)$; and for pathways in cancer $(\mathrm{q}<0.001)$ (Figure 8$)$.

\subsection{Changes in the Serum Level of Polyamines and Zonulin and Fecal Levels of SCFAs after RCT Treatment in CRC Patients}

Significant differences in the serum levels of several polyamines and acetyl derivatives of polyamines were found in the R and NR patients at post-treatment point (T3). Then, in the NR patients, we found a significant increase in the levels of spermine, N1-acetyl spermine (N1-AcSP), N1, N12-diacetylspermine (N1, N12-DiAcSP), N1-acetylspermidine 
(N1-AcSPD), N1, N8- diacetylspermidine (N1, N8-DiAcSPD), and N1-acetylputrescine (N1-AcPUT) compared to those in the R patients. On the other hand, within-group, there were also significant changes in the levels of N1-AcSPD and spermine in both the R and NR patients and in the serum levels of N8-AcSPD only in the NR group (Table 2).
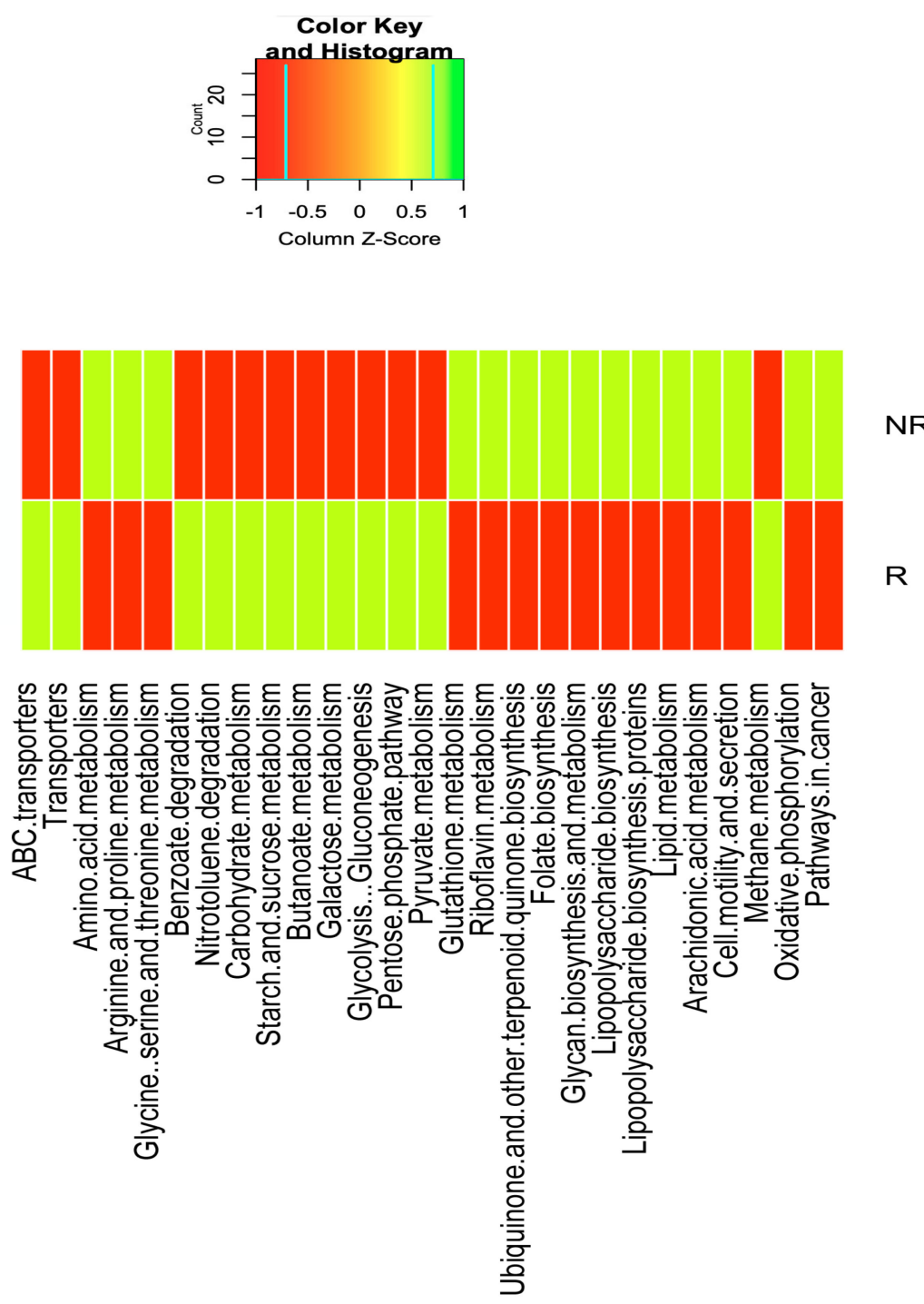

Figure 8. Heatmap of bacterial gene functional predictions using the PICRUSt algorithm from the fecal samples from the responder (R) patients and the non-responder (NR) patients.

Table 2. Serum polyamines levels at baseline (T0) and post-treatment (T3).

\begin{tabular}{|c|c|c|c|c|}
\hline & $\begin{array}{l}\text { R Patients } \\
(\mathrm{N}=\mathbf{2 8})\end{array}$ & $\begin{array}{l}\text { NR Patients } \\
\quad(\mathrm{N}=12)\end{array}$ & $\begin{array}{l}\text { Between-Group } \\
\text { Difference }^{1}\end{array}$ & $p^{2}$ \\
\hline $\begin{array}{c}\text { Agmatine }(\mathrm{ng} / \mathrm{mL}) \\
\text { Baseline } \\
\text { Post-treatment } \\
\text { Change }\end{array}$ & $\begin{array}{c}0.11 \pm 0.13 \\
0.25 \pm 0.24 \\
0.14(-0.27,-0.13)\end{array}$ & $\begin{array}{c}0.13 \pm 0.15 \\
0.17 \pm 0.15 \\
0.035(-0.13,0.061)\end{array}$ & $0.025(-0.11,0.63)$ & 0.571 \\
\hline $\begin{array}{c}\text { Arginine }(\mu \mathrm{g} / \mathrm{mL}) \\
\text { Baseline } \\
\text { Post-treatment } \\
\text { Change }\end{array}$ & $\begin{array}{c}23.18 \pm 4.20 \\
22.82 \pm 4.16 \\
-0.36(-1.5,2.27)\end{array}$ & $\begin{array}{c}24.54 \pm 4.76 \\
23.10 \pm 4.48 \\
-1.43(-1.13,4.0)\end{array}$ & $-1.35(-4.05,1.35)$ & 0.319 \\
\hline
\end{tabular}


Table 2. Cont.

\begin{tabular}{|c|c|c|c|c|}
\hline & $\begin{array}{l}\text { R Patients } \\
(\mathrm{N}=28)\end{array}$ & $\begin{array}{l}\text { NR Patients } \\
\quad(\mathrm{N}=12)\end{array}$ & $\begin{array}{l}\text { Between-Group } \\
\text { Difference }^{1}\end{array}$ & $p^{2}$ \\
\hline $\begin{array}{l}\text { Ornithine }(\mu \mathrm{g} / \mathrm{mL}) \\
\text { Baseline } \\
\text { Post-treatment } \\
\text { Change }\end{array}$ & $\begin{array}{c}19.46 \pm 5.74 \\
20.21 \pm 4.16 \\
0.74(-3.69,2.19)\end{array}$ & $\begin{aligned} 23.31 & \pm 8.06 \\
22.80 & \pm 7.55 \\
-0.51(-3.72,4.74) & \end{aligned}$ & $-3.85(-8.07,0,37)$ & 0.073 \\
\hline $\begin{array}{c}\text { N1,N12-diacetylspermine }(\mathrm{ng} / \mathrm{mL}) \\
\text { Baseline } \\
\text { Post-treatment } \\
\text { Change }\end{array}$ & $\begin{array}{c}1.08 \pm 0.43 \\
0.90 \pm 0.52 \\
-0.18(0.017,0.34)\end{array}$ & $\begin{array}{c}1.68 \pm 1.34 \\
1.22 \pm 0.57 \\
0.46(-0.152,1.07)\end{array}$ & $-0.59(-1.20,0.06)$ & 0.015 \\
\hline $\begin{array}{c}\text { N1,N8-diacetylspermidine }(\mathrm{ng} / \mathrm{mL}) \\
\text { Baseline } \\
\text { Post-treatment } \\
\text { Change }\end{array}$ & $\begin{array}{c}0.71 \pm 0.26 \\
0.74 \pm 0.34 \\
0.03(-0.13,0.059)\end{array}$ & $\begin{array}{c}0.99 \pm 1.03 \\
0.88 \pm 0.38 \\
-0.11(-0.34,0.57)\end{array}$ & $-0.28(-0.74,0.17)$ & 0.007 \\
\hline $\begin{array}{c}\text { N1-acetylspermidine }(\mathrm{ng} / \mathrm{mL}) \\
\text { Baseline } \\
\text { Post-treatment } \\
\text { Change }\end{array}$ & $\begin{array}{c}22.47 \pm 7.10 \\
23.42 \pm 8.26 \\
0.94(-3.88,1.99) *\end{array}$ & $\begin{array}{c}27.68 \pm 13.47 \\
28.89 \pm 10.38 \\
1.20(-6.10,3.68) *\end{array}$ & $-5.21(-11.73,1.3)$ & 0.021 \\
\hline $\begin{array}{c}\text { N8-acetylspermidine }(\mathrm{ng} / \mathrm{mL}) \\
\text { Baseline } \\
\text { Post-treatment } \\
\text { Change }\end{array}$ & $\begin{array}{c}14.52 \pm 3.48 \\
14.69 \pm 3.39 \\
0.16(-0.90,0.57)\end{array}$ & $\begin{array}{c}14.88 \pm 3.27 \\
16.10 \pm 2.33 \\
1.22(-2.42,-0.20) *\end{array}$ & $-0.35(-2.38,1.67)$ & 0.727 \\
\hline $\begin{array}{l}\text { N1-acetylputrescine }(\mathrm{ng} / \mathrm{mL}) \\
\text { Baseline } \\
\text { Post-treatment } \\
\text { Change }\end{array}$ & $\begin{array}{c}5.04 \pm 1.60 \\
4.77 \pm 1.70 \\
-0.27(-1.78,1.09)\end{array}$ & $\begin{array}{c}5.92 \pm 5.38 \\
5.39 \pm 3.79 \\
-0.53(-1.01,3.32)\end{array}$ & $-0.88(-3.29,1.53)$ & 0.030 \\
\hline $\begin{array}{l}\text { Putrescine }(\mathrm{ng} / \mathrm{mL}) \\
\text { Baseline } \\
\text { Post-treatment } \\
\text { Change }\end{array}$ & $\begin{array}{c}8.84 \pm 4.40 \\
8.06 \pm 3.89 \\
-0.78(-0.39,1.96)\end{array}$ & $\begin{array}{c}7.95 \pm 3.52 \\
7.47 \pm 3.09 \\
-0.47(-1.07,2.02)\end{array}$ & $0.89(-1.49,3.28)$ & 0.457 \\
\hline $\begin{array}{c}\text { Spermidine }(\mathrm{ng} / \mathrm{mL}) \\
\text { Baseline } \\
\text { Post-treatment } \\
\text { Change }\end{array}$ & $\begin{array}{c}17.14 \pm 7.19 \\
20.42 \pm 12.40 \\
3.28(-7.42,0.85)\end{array}$ & $\begin{array}{c}22.26 \pm 12.69 \\
20.90 \pm 10.81 \\
-1.35(-2.01,4.73)\end{array}$ & $-4.11(-11.36,1.12)$ & 0.106 \\
\hline $\begin{array}{c}\text { N1-acetylspermine }(\mathrm{ng} / \mathrm{mL}) \\
\text { Baseline } \\
\text { Post-treatment } \\
\text { Change }\end{array}$ & $\begin{array}{c}0.89 \pm 0.33 \\
1.19 \pm 0.63 \\
0.29(-0.55,-0.046)\end{array}$ & $\begin{array}{c}1.48 \pm 0.70 \\
1.33 \pm 0.62 \\
-0.14(-0.11,0.40)\end{array}$ & $-0.58(-0.92,-0.25)$ & 0.014 \\
\hline $\begin{array}{l}\text { Spermine }(\mathrm{ng} / \mathrm{mL}) \\
\text { Baseline } \\
\text { Post-treatment } \\
\text { Change }\end{array}$ & $\begin{array}{c}3.77 \pm 1.30 \\
4.80 \pm 2.88 \\
1.03(-2.17,0.107) *\end{array}$ & $\begin{array}{c}12.10 \pm 7.85 \\
7.35 \pm 3.66 \\
-4.74(1.71,7.77) *\end{array}$ & $-7.32(-11.74,-4,89)$ & 0.001 \\
\hline
\end{tabular}

Serum polyamine levels were measured by means of ultra-high performance liquid chromatography tandem mass spectrometry (UHPLCMS/MS). Values are expressed as mean \pm SD or mean $(95 \% \mathrm{CI})$. R: responder; NR: non-responder. ${ }^{1}$ Difference between $\mathrm{R}$ and NR patients at post-treatment when adjusted for baseline. ${ }^{2}$ Comparison among post-treatment changes was conducted with a covariance model (ANCOVA) adjusted for baseline. ${ }^{*}$ Wilcoxon signed-rank test was used to calculate differences in polyamines between baseline and post-treatment in $\mathrm{R}$ and NR patients. $p<0.05$ was considered statistically significant.

SCFAs are bacterial-derived metabolites with important physiological functions in the host and that have anti-cancer properties. Analysis of the fecal levels of SCFAs revealed significant differences in the concentrations of acetic, butyric, isobutyric, valeric, isovaleric, and hexanoic acid between the R and NR study groups at post-treatment time point $\mathrm{T} 3$. Moreover, we found several significant differences in the within-group comparison of the fecal concentrations of acetic and butyric acid, which significantly increased after RCT treatment in the R group. On the other hand, serum zonulin levels (a circulating marker of gut permeability) were significantly increased in the NR group (but not in R group) after RCT treatment (Table 3). 
Table 3. Fecal SCFAs concentrations and serum zonulin levels at baseline (T0) and post-treatment (T3).

\begin{tabular}{|c|c|c|c|c|}
\hline & $\begin{array}{l}\text { R Patients } \\
(\mathrm{N}=\mathbf{2 8})\end{array}$ & $\begin{array}{l}\text { NR Patients } \\
\quad(\mathrm{N}=12)\end{array}$ & $\begin{array}{l}\text { Between-Group } \\
\text { Difference }^{1}\end{array}$ & $p^{2}$ \\
\hline $\begin{array}{l}\text { Acetic acid }(\mathrm{mg} / \mathrm{g}) \\
\text { Baseline } \\
\text { Post-treatment } \\
\text { Change }\end{array}$ & $\begin{array}{c}0.83 \pm 0.39 \\
1.04 \pm 0.40 \\
0.20(-0.39,0.31) *\end{array}$ & $\begin{array}{c}0.71 \pm 0.15 \\
0.77 \pm 0.17 \\
0.06(-0.30,0.18)\end{array}$ & $0.26(-0.03,0.56)$ & 0.012 \\
\hline $\begin{array}{l}\text { Propionic acid }(\mathrm{mg} / \mathrm{g}) \\
\text { Baseline } \\
\text { Post-treatment } \\
\text { Change }\end{array}$ & $\begin{array}{c}1.40 \pm 1.27 \\
1.01 \pm 1.10 \\
-0.39(-0.51,0.59)\end{array}$ & $\begin{array}{c}2.02 \pm 1.35 \\
1.70 \pm 1.52 \\
-0.32(-0.9,0.36)\end{array}$ & $-0.68(-0.86,1.76)$ & 0.102 \\
\hline $\begin{array}{c}\text { Butyric acid }(\mathrm{mg} / \mathrm{g}) \\
\text { Baseline } \\
\text { Post-treatment } \\
\text { Change }\end{array}$ & $\begin{array}{c}1.37 \pm 0.45 \\
2.36 \pm 1.82 \\
0.99(-1.2,2.15) *\end{array}$ & $\begin{array}{c}0.93 \pm 0.68 \\
1.02 \pm 1.07 \\
0.09(-0.65,1.34)\end{array}$ & $1.33(-0.04,2.71)$ & 0.016 \\
\hline $\begin{array}{l}\text { Isobutyric acid }(\mathrm{mg} / \mathrm{g}) \\
\text { Baseline } \\
\text { Post-treatment } \\
\text { Change }\end{array}$ & $\begin{array}{c}0.58 \pm 0.33 \\
0.69 \pm 0.05 \\
0.11(0.07,0.21)\end{array}$ & $\begin{array}{c}0.31 \pm 0.33 \\
0.44 \pm 0.15 \\
-0.13(-0.23,0.76)\end{array}$ & $0.15(0.03,0.26)$ & 0.010 \\
\hline $\begin{array}{l}\text { Valeric acid }(\mathrm{mg} / \mathrm{g}) \\
\text { Baseline } \\
\text { Post-treatment } \\
\text { Change }\end{array}$ & $\begin{array}{c}0.30 \pm 0.16 \\
0.13 \pm 0.07 \\
-0.17(-0.27,0.39)\end{array}$ & $\begin{array}{c}0.61 \pm 0.32 \\
0.29 \pm 0.19 \\
-0.47(-0.58,0.76)\end{array}$ & $-0.25(-0.38,0.29)$ & 0.002 \\
\hline $\begin{array}{l}\text { Isovaleric acid }(\mathrm{mg} / \mathrm{g}) \\
\text { Baseline } \\
\text { Post-treatment } \\
\text { Change }\end{array}$ & $\begin{array}{c}0.50 \pm 0.49 \\
0.20 \pm 0.13 \\
-0.30(-0.43,0.31)\end{array}$ & $\begin{array}{c}0.90 \pm 0.44 \\
0.39 \pm 0.24 \\
-0.51(0.66,1.02)\end{array}$ & $-0.18(-0.45,0.29)$ & 0.009 \\
\hline $\begin{array}{c}\text { 4-methylvaleric acid }(\mathrm{mg} / \mathrm{g}) \\
\text { Baseline } \\
\text { Post-treatment } \\
\text { Change }\end{array}$ & $\begin{array}{c}0.13 \pm 0.23 \\
0.07 \pm 0.10 \\
-0.06(-0.09,0.15)\end{array}$ & $\begin{array}{c}0.37 \pm 0.64 \\
0.04 \pm 0.01 \\
-0.33(-0.47,0.86)\end{array}$ & $0.20(-0.35,0.10)$ & 0.216 \\
\hline $\begin{array}{c}\text { Hexanoic acid }(\mathrm{mg} / \mathrm{g}) \\
\text { Baseline } \\
\text { Post-treatment } \\
\text { Change }\end{array}$ & $\begin{array}{c}0.15 \pm 0.20 \\
0.10 \pm 0.10 \\
-0.04(-0.09,0.10)\end{array}$ & $\begin{array}{c}0.11 \pm 0.08 \\
0.05 \pm 0.09 \\
-0.05(-0.07,0.13)\end{array}$ & $0.05(-0.19,0.13)$ & 0.007 \\
\hline $\begin{array}{c}\text { Heptanoic acid }(\mathrm{mg} / \mathrm{g}) \\
\text { Baseline } \\
\text { Post-treatment } \\
\text { Change }\end{array}$ & $\begin{array}{c}0.09 \pm 0.15 \\
0.06 \pm 0.06 \\
-0.03(-0.06,0.07)\end{array}$ & $\begin{array}{c}0.07 \pm 0.06 \\
0.05 \pm 0.01 \\
-0.02(-0.04,0.08)\end{array}$ & $0.02(-0.07,0.04)$ & 0.171 \\
\hline $\begin{array}{c}\text { Zonulin }(\mathrm{ng} / \mathrm{mL}) \\
\text { Baseline } \\
\text { Post-treatment } \\
\text { Change }\end{array}$ & $\begin{array}{c}257.6 \pm 65.4 \\
218.1 \pm 76.4 \\
-39.3(-52.2,23.9)\end{array}$ & $\begin{array}{c}272.6 \pm 35.1 \\
298.4 \pm 47.5 \\
25.2(11.3,37.1)\end{array}$ & $-22.2(-37.4,10.2)$ & 0.004 \\
\hline
\end{tabular}

Short-chain fatty acids (SCFAs) in fecal samples were analyzed by means of gas chromatography coupled with a flame-ionization detector (GC-FID). Values are expressed as mean \pm SD or mean $(95 \% \mathrm{CI})$. R: responder; NR: non-responder. ${ }^{1}$ Difference between $\mathrm{R}$ and NR patients at post-treatment when adjusted for baseline. ${ }^{2}$ Comparison among post-treatment changes was conducted with a covariance model (ANCOVA) adjusted for baseline. * Wilcoxon signed-rank test was used to calculate differences in the SCFAs and zonulin between the baseline and post-treatment in R and NR patients. $p<0.05$ was considered statistically significant.

In addition, pairwise comparisons using Spearman rank correlation analysis were then performed between bacterial species enriched in the gut microbiome of both the $\mathrm{R}$ and NR patients and the fecal SCFAs and serum polyamines and zonulin levels. Interestingly, we found a statistically significant positive correlation between the fecal levels of butyrate and the abundance of the Faecalibacterium prausnitzii $(\mathrm{r}=0.816 p<0.001)$ and Ruminoccocus albus $(\mathrm{r}=0.924 p=0.008)$ in the $\mathrm{R}$ group and between the concentration of propionic acid and Bacteroides fragilis in the NR group. In addition, negative associations of Faecalibacterium prausnitzii with the serum levels of spermine $(\mathrm{r}=-0.619 p=0.018)$ and N1,N12-DiAcSP $(\mathrm{r}=-0.793 p=0.01)$ in the $\mathrm{R}$ patients were described, while there was a positive association between the abundance of Bacteroides fragilis and Fusobacterium nucleatum with the levels of N1,N12-DiAcSP ( $\mathrm{r}=0.436 p=0.043 ; \mathrm{r}=0.637 p=0.001$, respectively) and N8-AcSPD 
$(\mathrm{r}=0.547 p=0.014 ; \mathrm{r}=0.752 p<0.001)$ in the NR patients. Finally, Prevotella copri was positively associated with the serum zonulin levels in NR patients.

\section{Discussion}

In this study, we have demonstrated the existence of a significant association between the gut microbiota and the anti-cancer response of CRC patients treated with neoadjuvant RCT. Moreover, we have found that some microbial-derived metabolites such as SCFAs could be at least partially responsible for the response to RCT in these CRC patients. Finally, we have identified a baseline consortium of CRC-enriched bacterial species that may potentially serve as diagnostic bacterial markers of a good or bad response to neoadjuvant RCT. Where Ruminococcus albus, Bifidobacterium bifidum, and Faecalibacterium prausnitzii, were overrepresented in $\mathrm{R}$ patients and chosen as discriminatory variables in our responseprediction RF model, Fusobacterium nucleatum and Bacteroides fragilis were overrepresented in the NR patients.

The loss of microbial diversity has been associated with chronic health conditions [25-27] and cancer [27,28] as well as with poor outcomes to certain forms of cancer therapy [29-31]. Accordingly, recent works have also reported that patients with CRC display a lower bacterial diversity and richness in fecal samples and the intestinal mucosa compared to healthy individuals $[32,33]$. In this study, we found that compared to healthy controls, the CRC microbiota exhibited a state of dysbiosis with a reduced overall bacterial richness and diversity. In addition, the analysis of the Bray-Curtis PCoA plot for beta diversity revealed that the CRC patients were clustered separately to the healthy controls, suggesting important CRC-mediated microbial changes.

Related to gut microbiota composition, several microbes have been found to be differentially represented in fecal samples between both study groups. Thus, the gut microbiota in the CRC patients was enriched with pro-inflammatory opportunistic pathogens and was depleted in butyrate-producing bacteria, which have been shown to be essential for the preservation of intestinal homeostasis [34]. In particular, we have shown that some bacteria such as Fusobacterium nucleatum, Escherichia coli, and Bacteroides fragilis had high prevalence in CRC patients in comparison to the healthy controls, whereas genera such as Roseburia, Faecalibacterium, and Bifidobacterium were depleted, demonstrating that microbial dysbiosis was already present in CRC at the time of diagnosis.

On the other hand, we observed that gut microbiota composition was relatively stable over treatment time following RCT treatment, with the exception of a significant decrease in the abundance of Fusobacterium, Escherichia, and Klebsiella and a significant increase in Bifidobacterium (probiotic bacteria) at post-treatment time compared to at baseline, showing the beneficial effect of RCT on the gut microbiome of CRC patients. Klebsiella and Fusobacterium are pathogens normally found in the human intestine that cause diarrhea and bloodstream infections and that considerably increase the rates of treatment failure and death [35].

After treatment, the CRC patients were classified as responders $(\mathrm{N})$ versus nonresponders (NR), based on their good or poor response to the RCT. Interestingly, we found significant differences in the alpha diversity at the genus level, with an increase in the diversity (Shannon) and richness (Chao 1) in the R patients compared to in the NR patients. Similarly, there was a statistically significant difference in B-diversity (Bray-Curtis dissimilarities and Jaccard index), finding a notable clustering effect by response status in the gut microbiome of these patients, indicating a difference in the bacterial community composition between the $\mathrm{R}$ and NR patients.

At the taxa levels, we found a significant enrichment in probiotic and butyrate producer-bacteria such as Bifidobacterium bifidum, Ruminoccous albus, Roseburia, and Faecalibacterium prausnitzii in the R patients, while the NR patients showed an enrichment in unfavorable microbial taxa such as Fusobacterium nucleatum, Bacteroides fragilis, Escherichia coli, Prevotella copri, and Klebsiella. Several studies have shown that butyrate-producing bacteria are negatively related to irritable bowel disease and colorectal cancer [36,37]. 
Additionally, both Fusobacterium and Prevotella have been related to recurrent CRC after chemotherapy. Given that Fusobacterium nucleatum has been previously correlated with chemoresistance [17], our results may suggest that the higher load of Fusobacterium nucleatum present in NR patients could be a potential promoter of CRC chemoresistance and therefore of a poor response to CRC treatment. Similarly, the enterotoxigenic Bacteroides fragilis, which was also enriched in the NR patients, is a significant source of chronic inflammation, and it has previously been associated with the development and aggressiveness of colorectal cancer and poor patient outcome [6,38]. These data also suggest that the gut microbiota composition of the $\mathrm{R}$ patients shifted towards a microbial profile that has great similarity to the gut microbiota of the healthy controls.

Next, we sought to gain insight into the mechanism through which the gut microbiome may influence response to RCT. Regarding the metabolic function of gut microbiota, in the current study, Picrust analysis showed significant differences between the R and NR patients. In the NR patients, we have found an increase in the abundance of genes for lipopolysaccharide biosynthesis as well as for araquidonic acid metabolism, for glutathione metabolism, and for the amino acid metabolism pathways (such as arginine and proline metabolism) compared to in the R patients. The significant increase of genes for lipopolysaccharide biosynthesis could be related to the significant increase in the abundance of Gram-negative bacteria such as Escherichia coli in the NR patients; these bacteria contain specific enzymes that produce LPS, which can induce Toll-like receptor 4 signaling and can promote cell survival and proliferation in CRC patients [39]. Similarly, the arachidonic acid pathway is important in the development and progression of numerous malignant diseases, including $C R C$, due to the fact that araquidonic acid stimulates key downstream signaling cascades that regulate cell proliferation, apoptosis, angiogenesis, inflammation, and immune surveillance [40,41]. With respect to the increase in the genes for glutathione metabolism in NR patients, some studies have described that the elevated levels of glutathione in tumor cells are able to protect such cells in bone marrow, breast, colon, larynx, and lung cancers by conferring resistance to several chemotherapeutic drugs [42,43]. Other bacterial functions involving the metabolism of cofactors and vitamins and the energy production pathways such as oxidative phosphorylation were also increased in NR patients. These pathways may serve as alternative bioenergetic sources for metabolically stressed cancer cells [44].

Remarkably, a recent metagenomic analysis reported that the CRC-associated microbiome showed an association with the conversion of amino acids into polyamines (e.g., the biosynthesis of putrescine from the amino acids L-arginine and L-ornithine), indicating that these metabolites could be particularly important in CRC development and progression [45]. In our study, significant differences in the serum levels of several polyamines and acetyl derivatives of polyamines were found between $\mathrm{R}$ and NR patients at post-treatment point. Moreover, we observed that the abundance of N1,N12-DiAcSP and N8-AcSPD were positively associated with the increased abundance of Bacteroides fragilis and Fusobacterium nucleatum in NR patients.

In fact, Bacteroides spp. and Fusobacterium spp. can synthesize putrescine and spermidine in vitro and in vivo [46]. Goodwin et al. demonstrated that the purified Bacteroides fragilis toxin (BFT) up-regulates spermine oxidase in HT29/c1 and T84 colonic epithelial cells, producing the spermine oxidase-dependent generation of ROS and the induction of a marker of DNA damage such as $\gamma$-H2A.x. [47]. In another study, Johnson et al. found that antibiotic treatment led to a lower tissue concentration of N1, N12diacylspermine and that a disturbed bacterial biofilm was observed in resected CRC tissues compare to CRC tissues with negative bacterial biofilm, suggesting the implication of gut microbes in the increase of host generated N1, N12-diacetylspermine [48]. Moreover, the activation of the amino acid metabolic pathways by the intestinal microbiota of the NR patients could contribute to the increase in polyamines, which are actively assimilated by the cells of the intestinal epithelium and induce rapid cell proliferation, favoring the tumorigenesis $[49,50]$. 
On the other hand, several works performed in both cellular and animal models have demonstrated that CRC is linked to alterations in the metabolism of SCFAs, which have been shown to exhibit potential anti-carcinogenic effects [51,52]. Here, we have found that $\mathrm{R}$ patients displayed a significant over-representation of genes involved in butanoate metabolism and a significant increase in the fecal abundance of several SCFAs such as acetic and butyric acid after RCT treatment. Moreover, there was a positive correlation between the fecal levels of butyrate and the abundance of Faecalibacterium prausnitzii and Ruminoccocus albus in these patients. Faecalibacterium praustnitzi is considered important in health promotion, as it is able to produce butyrate from dietary fibre and possesses anti-inflammatory properties [53]. A decrease in Faecalibacterium prausnitzii and butyrate levels defines microbiota dysbiosis in patients suffering inflammatory bowel disease [54]. In addition, Faecalibacterium is able to use the acetate produced by Bifidobacterium (also increased in $\mathrm{N}$ patients) with the subsequent modulation of the intestinal mucus barrier by the modification of goblet cells and mucin glycosylation [55]. Butyrate is required for colonic epithelium repair and the production of Treg cells, which regulate the local immune response and suppress colonic inflammation and carcinogenesis [56]. Moreover, butyrate has been described to be able to induce the production of IL-18 by the intestinal epithelial cells through the activation of the GPR109a receptor, which stimulates mucosal tissue repair via the regulation of the production and availability of IL-22 [57]. The absence of IL-18 has been associated with gut microbiota dysbiosis, a dysregulation of the homeostatic and mucosal repair and alteration of the inflammatory response, producing an increased susceptibility to carcinogenesis [58]. In addition, after RCT treatment, we found a significant decrease in the fecal levels of acetic, butyric, isobutyric, and hexanoic acid in the NR study group compared to in $\mathrm{R}$ patients, indicating the exhaustion of butyric acid-producing microbiota in their colon. In a previous study, hexanoic acid was shown to reduce the colonization and dysbiotic expansion of potentially pathogenic bacteria in the gut [59].

Finally, we found that plasma zonulin levels were significantly increased in the NR patients compared to in the R patients. A higher zonulin level was correlated with the relaive abundance of Prevotella copri in the $\mathrm{R}$ patients. Zonulin is a protein synthesized in intestinal and liver cells that reversibly modulates the intestinal permeability of the intestinal epithelial barrier by modulating intercellular tight junctions [60]. Wright et al. found that Prevotella contains key enzymes implicated in mucin degradation, which are able to disrupt the colonic mucus barrier. A disrupted mucosal barrier may result in increased intestinal permeability, which allows the diffusion of antigens, toxins, and pathogens from the luminal environment into the mucosal tissues and circulatory system [55]. As a consequence, an inflammatory response can be triggered that induces cancer initiation, progression, and response to anticancer treatment [61]. Then, the significant increase in Prevotella abundance found in our study could be associated in party with the poor or non-response to RCT in NR patients.

This study has some limitations, such as the relatively small sample size, which could reduce the power of the study. However, despite the relatively small size of our study, statistically significant differences were observed, suggesting that the results presented herein provide solid evidence on the potential contribution of the gut microbiome to RCT outcomes in CRC patients. Moreover, our study also has several strengths, such as the careful design, the well-matched cohorts of CRC patients and controls, a complete definition of the inclusion and exclusion criteria, and the consideration of lifestyle-associated confounding factors that may affect the gut microbiota composition, such as dietary pattern.

\section{Materials and Methods}

\subsection{Study Patients}

A total of forty patients aged 35-75-years-old who were newly diagnosed with CRC in stages II-III (T2-T4 and/or N1-N2) from the Radiotherapy Oncology Service at the Virgen de la Victoria Hospital and with no metastatic lesions detected on imaging were enrolled in the study and were followed-up with for at least 1 year. All of the CRC patients 
received only neoadjuvant treatment for 5 weeks with pelvic radiation therapy (50 Gy in fractions of 2 Gy/session) and oral capecitabine $\left(825 \mathrm{mg} / \mathrm{m}^{2} / 12 \mathrm{~h}\right)$ during radiotherapy treatment. Patients with a history of colorectal cancer or bowel resection, type 2 diabetes, chronic inflammatory bowel disease, severe active infection, or hereditary colorectal cancer syndromes were excluded from the study. Patients who received pelvic cancer radiation therapy or anti-tumor treatment in the previous 2 years, who used antibiotics or immunosuppressants in the previous 2 months, or who regularly used non-steroidal anti-inflammatory drugs, statins, or probiotics before the study were also excluded. A pathologist examined surgical specimens and tumor response after neoadjuvant RCT was determined in surgical specimens according to the tumor regression grades (TRG) system described by Mandard et al. [62]. We divided the CRC patients into TRG1-2 (patients with good response or responders (R)) and TRG 3-5 (patients with poor or non-response (NR)). Blood and fecal samples were collected at baseline (T0), 2 and 4 weeks after starting RCT (T1 and T2, respectively), and 7 weeks after finishing treatment (T3).

In the study, we also included fecal samples from 20 healthy patients that were matched with the CRC patients according to sex, age, and BMI. The healthy controls did not have gastrointestinal tract disorders or other complications and were not administered antibiotics or probiotics during the 2 months prior to sample collection.

The study protocol was approved by the Medical Ethics Committee at the Virgen de la Victoria University Hospital and was conducted in accordance with the Declaration of Helsinki. Written informed consent was provided by all study participants.

\subsection{Laboratory Measurements}

Fasting venous blood samples were collected, and serum was separated in aliquots and was immediately frozen at $-80^{\circ} \mathrm{C}$. Serum levels of glucose, total cholesterol, triglycerides, HDL-cholesterol, and LDL-cholesterol were measured in duplicate using a Dimension autoanalyzer (Dade Behring Inc., Deerfield, IL, USA) using enzymatic methods (Randox Laboratories Ltd. Ardmore, UK).

\subsection{DNA Extraction and Gut Microbiota Sequencing}

The frozen fecal samples were thawed at $4{ }^{\circ} \mathrm{C}$ to avoid dramatic temperature changes that might affect bacterial DNA integrity. Afterwards, the fecal samples were manually homogenized for $30 \mathrm{~s}$ with a sterile plastic scoop, and aliquots of $200 \mathrm{mg}$ were used for DNA extraction using the QIAamp DNA Stool Mini kit following the manufacturer's instructions (Qiagen, Hilden, Germany). DNA concentration (A260) and purity (A260/A280 ratio) were estimated with a Nanodrop spectrophotometer (Nanodrop Technologies, Wilmington, DE, USA).

DNA was amplified using the Ion 16S Metagenomics kit (Thermo Fisher Scientific, Madrid, Spain), which contains a primer pool to amplify multiple variable regions (V2, $3,4,6-7,8$ and 9) of the 16S rRNA gene. The Ion PlusTM Fragment Library Kit (Thermo Fisher Scientific, Madrid, Spain) was used to ligate the barcoded adapters to the generated amplicons and to create the barcoded libraries, which were pooled and templated on the automated Ion Chef system (Thermo Fisher Scientific, Madrid, Spain). The sequencing was done on an Ion S5 platform (Thermo Fisher Scientific, Madrid, Spain).

\subsection{Bioinformatics Analysis}

Analysis of 16S rRNA amplicons was performed using QIIME (2-2019.4 version). The q-dada2 plugin with the DADA2 pipeline was used for the quality filtering and the denoised, dereplicated, and chimera filtering of the raw sequence data. The sequence variants obtained through the DADA2 pipeline were merged into a single feature table using the q2-feature-table plugin. Using the q2-vsearch plugin with $97 \%$ sequence similarity, all amplicon sequence variants from the merged feature table were clustered into OTU's using the Open Reference Clustering method against Greengenes version 13_8 with $97 \%$ similarity from the OTU reference sequences. The OTUs were aligned with 
MAFFT (via q2-alignment) and were used to construct a phylogeny with fasttree2 (via q2-phylogeny). The q2-feature-classifier classify-sklearn naive Bayes taxonomy classifier was used to assign taxonomy to the OTUs. Alpha diversity metrics (Shannon and Chao1), beta diversity metrics (Bray-Curtis dissimilarity), and principal coordinate analysis (PCoA) were estimated using a q2-diversity plugin after the samples were rarefied to 994 sequences per sample. Alpha diversity significance was estimated with Kruskal-Wallis test, and beta diversity significance was estimated using the non-parametric ANOSIM test.

\subsection{Analysis of Short-Chain Fatty Acids (SCFAs) in Fecal Samples by Gas Chromatography (GC) Coupled with a Flame-Ionization Detector}

The fecal concentrations of SCFAs were measured by GC coupled with a flameionization detector as previously described [63-66] in the Servicios de Apoyo a la Investigación de la Universidad de Extremadura (SAIUEx). Briefly, $20 \mathrm{mg}$ of the fecal samples were homogenized manually using a spatula in $200 \mu \mathrm{L}$ of distilled water. Subsequently, $100 \mu \mathrm{L}$ of homogenized fecal samples were mixed with $40 \mathrm{mg}$ of sodium chloride, $20 \mathrm{mg}$ of citric acid, $40 \mu \mathrm{L}$ of $0.1 \mathrm{M}$ hydrochloric acid, and $200 \mu \mathrm{L}$ of butanol: tetrahydrofuran: acetonitrile (50:30:20). The samples were then vigorously vortexed for $3 \mathrm{~min}$ and were centrifuged at $14,870 \times g$ at room temperature for $10 \mathrm{~min}$. The supernatant was transferred to a new plastic tube, and $200 \mu \mathrm{L}$ of a benzyl alcohol-pyridine mixture (3:2) and $100 \mu \mathrm{L}$ DMSO were added, and the mixture was vortexed for $5 \mathrm{~s}$. Then, $100 \mu \mathrm{L}$ of benzyl chloroformate was added carefully. To release the gases generated by the reaction, the tube lid was kept open for $1 \mathrm{~min}$. The tube was then closed, and the mixture was vortexed. After derivatization, $200 \mu \mathrm{L}$ hexane was added to the reaction mixture, and the sample was vortexed for $5 \mathrm{~min}$ followed by a centrifugation step at $21,000 \times g$ for $2 \mathrm{~min}$. Subsequently, $100 \mu \mathrm{L}$ of derivative extract (upper hexane layer) was transferred to a glass insert, and $5 \mu \mathrm{L}$ were injected into the gas chromatograph and were further analyzed using an Agilent 6850 gas chromatograph coupled with a split/spitless injector and a flame-ionization detector (FID) (Agilent Technologies, Santa Clara, CA, USA).

The temperature of the injector and detector was adjusted to $250{ }^{\circ} \mathrm{C}$, and the samples $(5 \mu \mathrm{L})$ were injected in a split ratio of $25: 1$ using a fused-silica capillary DB-23 column Agilent $(60 \mathrm{~m} \times 0.25 \mathrm{~mm}$ (internal diameter) coated with a $0.15 \mu \mathrm{m}$ thick layer of $80.2 \%$ 1-methylnaphatalene. Nitrogen was used as the carrier gas at $1 \mathrm{~mL} / \mathrm{min}$ (hold $4 \mathrm{~min}$ ), reduced to $0.8 \mathrm{~mL} / \mathrm{min}$ (hold $1 \mathrm{~min}$ ) and then $0.6 \mathrm{~mL} / \mathrm{min}$ (hold $1 \mathrm{~min}$ ), and finally increased to $1 \mathrm{~mL} / \mathrm{min}$. The temperature of the FID detector was adjusted and maintained at $260{ }^{\circ} \mathrm{C}$, and the flow rates of $\mathrm{H}_{2}$, the air, and the make-up gas $\mathrm{N}_{2}$ were adjusted to $30 \mathrm{~mL} / \mathrm{min}, 350 \mathrm{~mL} / \mathrm{min}$, and $25 \mathrm{~mL} / \mathrm{min}$, respectively. The initial oven temperature was $100{ }^{\circ} \mathrm{C}$ (hold $2 \mathrm{~min}$ ), which was increased to $200^{\circ} \mathrm{C}$ at a rate of $15^{\circ} \mathrm{C} / \mathrm{min}$, and was finally maintained at $200{ }^{\circ} \mathrm{C}$ for $5 \mathrm{~min}$. The identity of the SCFAs detected in the fecal samples was confirmed through the comparison of their retention times and their mass spectra with those of the analytical SCFA standards (Sigma-Aldrich, Madrid, Spain). The standard calibration curves for SCFAs (acetic acid, propionic acid, butyric acid, isobutyric acid, valeric acid, isovaleric acid, 4- methylvaleric acid, hexanoic acid, and heptanoic acid) were prepared in triplicate, with a concentration range of $15-1,000 \mu \mathrm{g} / \mathrm{mL}$.

\subsection{Analysis of Serum Polyamine Levels by Ultra-High Performance Liquid Chromatography Tandem Mass Spectrometry (UHPLC-MS/MS)}

For the analysis of the polyamine concentrations, serum samples were processed as previously described [67]. Briefly, $50 \mu \mathrm{L}$ of serum (aliquoted in $1.5 \mathrm{~mL}$ Eppendorf LoBind tube) were mixed with $5 \mu \mathrm{L}$ of internal standard and $167 \mu \mathrm{L}$ of methanol. The mixture was vortexed for $1 \mathrm{~min}$, and $334 \mu \mathrm{L}$ of chloroform was added, vortexed for $1 \mathrm{~min}$, and centrifuged for $10 \mathrm{~min}$ at $15,000 \mathrm{rpm}$ and $4{ }^{\circ} \mathrm{C}$. After centrifugation, the upper layer was collected and was transferred to a new tube, where $100 \mu \mathrm{L}$ of carbonate-bicarbonate buffer ( $\mathrm{pH} 9$ ) and $50 \mu \mathrm{L}$ of dansyl chloride $(10 \mathrm{mg} / \mathrm{mL}$ in acetone) were added to derivatize the sample. The mixture was vortexed and was placed in the dark for $1 \mathrm{~h}$ at room temperature. A total of two extractions of the compounds were conducted with $250 \mu \mathrm{L}$ of ethyl acetate, 
between which $2.5 \mu \mathrm{L}$ of trifluoroacetic acid were added. A SpeedVac at $45^{\circ} \mathrm{C}$ was used to evaporat the combined organic phases, which were stored at $-20^{\circ} \mathrm{C}$ until analysis. An amount of $50 \mu \mathrm{L}$ of ammonium acetate and $0.2 \mathrm{M}$ acetonitrile (30:70) was used to reconstitute the samples.

Chromatography of the samples was completed with Agilent UHPLC 1290 series binary pump equipment (Agilent Technologies, Santa Clara, CA, USA), and the separation was performed on a Kinetex EVO C18 column $(2.6 \mu \mathrm{m}$ particle size, $2.1 \mathrm{~mm}$ internal diameter $\times 150 \mathrm{~mm}$ length) (Phenomenex, Torrance, CA, USA) held at $25^{\circ} \mathrm{C}$. A gradient was established between the water acidified with $0.1 \%$ formic acid (A), and acetonitrile acidified with $0.1 \%$ formic acid (B) at a flow rate of $400 \mu \mathrm{L} / \mathrm{min}$ was used as a mobile phase for elution. The injected amount was $2.5 \mu \mathrm{L}$.

MS/MS analysis was conducted in an Agilent QqQ 6490 Series mass spectrometer operating in AJS + ESI. The optimization of the ionization source parameters was performed as follows: nebulizer gas (nitrogen) with a pressure of $15 \mathrm{psi}$, a gas flow of $15 \mathrm{~L} / \mathrm{min}$ at $200{ }^{\circ} \mathrm{C}$, a sheath gas flow of $11 \mathrm{~L} / \mathrm{min}$ at $350^{\circ} \mathrm{C}$, a capillary voltage of $2.5 \mathrm{kV}$, and a nozzle voltage of $1000 \mathrm{~V}$ in a MassHunter Optimizer (Agilent Technologies, version 6.0)

An Agilent UHPLC 1290 Infinity II Series coupled to an Agilent QqQ/MS 6490 Series (Agilent Technologies, Sta. Clara, CA, USA) was used for LC-MS/MS analysis, while chromatographic separation was performed using a Kinetex EVO C18 analytical column $(2.6 \mu \mathrm{m} ; 2.1 \mathrm{~mm} \times 150 \mathrm{~mm})$ (Phenomenex, Torrance, CA, USA)

Quantification was completed with the commercial standards ornithine, spermine, arginine, spermidine, putrescine, N1-acetylspermidine, N8-acetylspermidine, N1-acetylspermine, N1-acetylputrescine, N1,N8-diacetylspermidine, and N1,N12-diacetylspermine (Toronto Research Chemicals, North York, ON, Canada). The internal standards of the amino acids were arginine $(13 \mathrm{C} 6,15 \mathrm{~N} 4)$ and lysine $(13 \mathrm{C} 6,15 \mathrm{~N} 2)$ (Cambridge Isotope Laboratories), and for the polyamines, the internal stanfdards comprised putrescine-d8, spermidine-d6, spermine-d20, and N8-acetylspermidine-d3 (Toronto Research Chemicals).

\subsection{Intestinal Permeability Analysis}

Plasma levels of zonulin were measured in duplicate using an ELISA commercial kit (Immunodiagnostik AG, Bensheim, Germany). Mean values were used for data analysis. Intra- and inter-assay coefficients of variation were between 3-10\%, and the detection limit was $0.22 \mathrm{ng} / \mathrm{mL}$.

\subsection{Statistical Analysis}

The Kruskal-Wallis rank-sum test was performed to compare the bacterial abundance between the study groups, and the false discovery rate (FDR) using the BenjaminiHochberg method was applied to correct the significant $\mathrm{p}$-values $(\mathrm{q}<0.05)$. The KruskalWallis rank-sum test and subsequent post hoc Bonferroni were used to analyze differences in the clinical and biochemical variables between three study groups, whereas differences between the two groups were analyzed using the Mann-Whitney U test. Inter-group comparison among post-treatment changes in fecal SCFAs and plasma zonulin levels were performed using a covariance model (ANCOVA) adjusted for baseline. A Wilcoxon signed-rank test was used to calculate differences in fecal SCFAs and plasma zonulin between baseline and the post-treatment timepoint T3. The Spearman correlation coefficients were calculated to estimate the correlations between the bacterial taxa and microbial derived-metabolites (SCFAs and polyamines) and the permeability. Statistical analyses were conducted with the statistical software package SPSS version 26.0 (SPSS Inc., Chicago, IL, USA). Random forests (RF) were used to predict baseline bacteria (species-level relative abundance data) related to the neoadjuvant RCT response using the default parameters of the $\mathrm{R}$ implementation of the algorithm (R package "randomForest"), and bootstrapping ( $\mathrm{n}$ $=500)$ was used to assess the classification accuracy. P values below 0.05 were considered statistically significant. 


\section{Conclusions}

In this study, we have demonstrated that the gut microbiota in CRC patients differs in intestinal microbiota composition in comparison with healthy controls. In CRC patients, the gut microbiota is characterized by a significantly lower bacterial diversity and richness, a significant increase in proinflammatory opportunistic pathogens, and a decrease in the relative abundance of beneficial or commensal butyrate-producing bacteria.

In addition, neoadjuvant RCT treatment did not induce significant changes in gut microbiota diversity and composition, with the exception of a significant decrease in Fusobacterium, Escherichia, and Klebsiella and a significant increase in Bifidobacterium at post-treatment time compared to baseline. Nevertheless, after the classification of CRC patients in the R and NR groups to the neoadjuvant RCT, we observed a significant increase in the diversity and richness in R patients compared to in the NR patients. Additionally, a compositional change was shown between both study patient groups, with a significant enrichment of probiotic and butyrate-producing bacteria in the $\mathrm{R}$ patients, accompanied by an enrichment in unfavorable pro-inflammatory bacteria in the NR patients. Moreover, the NR patients had significantly higher levels of spermine and some acetyl derivatives of polyamines and serum zonulin and significantly lower levels of fecal of acetic, butyric, isobutyric, and hexanoic acids than the R patients. These microbial-derived metabolites are important factors that connect the intestinal microbiota to CRC and could be responsible for RCT efficiency. Moreover, in the NR patients, the PICRUSt analysis found an over-representation of genes involved in lipopolysaccharide biosynthesis as well as in araquidonic acid and glutathione metabolism, genes from pathways associated with bacterial pathogenesis, inflammation, cell survival, proliferation, and therapy response.

In addition, we also identified a baseline consortium of CRC-enriched bacterial species (Ruminococcus albus, Bifidobacterium bifidum, Faecalibacterium prausnitzii, Fusobacterium nucleatum, and Bacteroides fragilis) that potentially could predict cancer treatment outcome, suggesting that the intestinal composition in CRC patients is important in predicting the response of the gut microbiome to neoadjuvant RCT. Altogether, our results suggest that a healthy gut microbiome could be indispensable for an optimum therapeutic response and that dysbiotic microbiota could be the underlying reason for variable responses to similar therapeutic strategies in different patients.

Supplementary Materials: The following are available online at https:/ /www.mdpi.com/article/10 $.3390 /$ ijms22179549/s1.

Author Contributions: Conceptualization, M.I.Q.-O. and J.G.-M.; methodology, L.S.-A., A.L.-I., B.R.-M., I.P.-A. and A.G.-G.; Investigation, L.S.-A., B.R.-M., I.P.-A., A.L.-I., A.O., R.O. and A.G.-G.; validation, L.S.-A., A.O., R.O., I.P.-A. and A.G.-G.; writing—original draft preparation, M.I.Q.-O., J.G.-M., L.S.-A. and B.R.-M.; writing—review and editing, all authors; funding acquisition, M.I.Q.-O.; supervision, M.I.Q.-O. and J.G.-M. All authors have read and agreed to the published version of the manuscript.

Funding: This work was supported by PI15/00256 from the Institute of Health "Carlos III" (ISCIII), co-funded by the Fondo Europeo de Desarrollo Regional-FEDER. Maria Isabel Queipo-Ortuño was supported by the "Miguel Servet Type II" program (CPI18/00003, ISCIII, Spain, co-funded by the Fondo Europeo de Desarrollo Regional-FEDER) and by the "Nicolas Monardes" research program of the Consejería de Salud (C-0030-2018, Junta de Andalucía, Spain. Bruno Ramos Molina was supported by the "Miguel Servet Type I" program (CP19/00098, ISCIII, Spain, co-funded by the Fondo Europeo de Desarrollo Regional-FEDER). Lidia Sanchez-Alcoholado was the recipient of a predoctoral grant (PE-0106-2019) from the Consejería de Salud y Familia (co-funded by the Fondo Europeo de Desarrollo Regional-FEDER, Andalucia, Spain). Aurora Laborda-Illanes was the recipient of a predoctoral grant, PFIS-ISCIII (FI19-00112), co-funded by the Fondo Europeo de Desarrollo Regional-FEDER, Madrid, Spain.

Institutional Review Board Statement: The study was conducted according to the guidelines of the Declaration of Helsinki and was approved by the Ethics Committee of Virgen de la Victoria University Hospital (30 October 2015). 
Informed Consent Statement: Informed consent was obtained from all subjects involved in the study.

Data Availability Statement: The data presented in this study are available upon request from the corresponding author. The data are not publicly available, as they contain information that could compromise the privacy of research participants.

Conflicts of Interest: The authors declare no conflict of interests.

\section{References}

1. Arnold, D.; Lueza, B.; Douillard, J.Y.; Peeters, M.; Lenz, H.J.; Venook, A.; Heinemann, V.; Van Cutsem, E.; Pignon, J.P.; Tabernero, J.; et al. Prognostic and predictive value of primary tumour side in patients with RAS wild-type metastatic colorectal cancer treated with chemotherapy and EGFR directed antibodies in six randomized trials. Ann. Oncol. 2017, 28, 1713-1729. [CrossRef]

2. Liang, Q.; Chiu, J.; Chen, Y.; Huang, Y.; Higashimori, A.; Fang, J.; Brim, H.; Ashktorab, H.; Ng, S.C.; Ng, S.S.M.; et al. Fecal bacteria act as novel biomarkers for noninvasive diagnosis of colorectal cancer. Clin. Cancer Res. 2017, 23, 2061-2070. [CrossRef]

3. Yazici, C.; Wolf, P.G.; Kim, H.; Cross, T.L.; Vermillion, K.; Carroll, T.; Augustus, G.J.; Mutlu, E.; Tussing-Humphreys, L.; Brauschweig, C.; et al. Race-dependent association of sulfidogenic bacteria with colorectal cancer. Gut 2017, 66, 1983-1994. [CrossRef] [PubMed]

4. Yu, J.; Feng, Q.; Wong, H.S.; Zhang, D.; Liang, Q.Y.; Qin, Y.; Tang, L.; Zhao, H.; Stenvang, J.; Li, Y.; et al. Metagenomic analysis of faecal microbiome as a tool towards targeted non-invasive biomarkers for colorectal cancer. Gut 2017, 66, 70-78. [CrossRef] [PubMed]

5. Helmink, B.A.; Khan, M.A.W.; Hermann, A.; Gopalakrishnan, V.; Wargo, J.A. The microbiome, cancer, and cancer therapy. Nat. Med. 2019, 25, 377-388. [CrossRef] [PubMed]

6. McQuade, J.L.; Daniel, C.R.; Helmink, B.A.; Wargo, J.A. Modulating the microbiome to improve therapeutic response in cancer. Lancet Oncol. 2019, 20, e77-e91. [CrossRef]

7. Yi, Y.; Shen, L.; Shi, W.; Xia, F.; Zhang, H.; Wang, Y.; Zhang, J.; Wang, Y.; Sun, X.; Zhang, Z.; et al. Gut microbiome components predict response to neoadjuvant chemoradiotherapy in patients with locally advanced rectal cancer: A prospective, longitudinal study. Clin. Cancer Res. 2021, 27, 1329-1340. [CrossRef] [PubMed]

8. Alexander, J.L.; Wilson, I.D.; Teare, J.; Marchesi, J.R.; Nicholson, J.K.; Kinross, J.M. Gut microbiota modulation of chemotherapy efficacy and toxicity. Nat. Rev. Gastroenterol. Hepatol. 2017, 14, 356-365. [CrossRef] [PubMed]

9. Sauer, R.; Becker, H.; Hohenberger, W.; Rödel, C.; Wittekind, C.; Fietkau, R.; Martus, P.; Tschmelitsch, J.; Hager, E.; Hess, C.F.; et al. Preoperative versus postoperative chemoradiotherapy for rectal cancer. N. Engl. J. Med. 2004, 351, 1731-1740. [CrossRef]

10. Ma, B.; Gao, P.; Wang, H.; Xu, Q.; Song, Y.; Huang, X.; Sun, J.; Zhao, J.; Luo, J.; Sun, Y.; et al. What has preoperative radio(chemo)therapy brought to localized rectal cancer patients in terms of perioperative and long-term outcomes over the past decades? A systematic review and meta-analysis based on 41,121 patients. Int. J. Cancer 2017, 141, 1052-1065. [CrossRef]

11. Pouncey, A.L.; Scott, A.J.; Alexander, J.L.; Marchesi, J.; Kinross, J. Gut microbiota, chemotherapy and the host: The influence of the gut microbiota on cancer treatment. Ecancermedicalscience 2018, 12, 868. [CrossRef]

12. Koppel, N.; Maini Rekdal, V.; Balskus, E.P. Chemical transformation of xenobiotics by the human gut microbiota. Science 2017, 356, eaag2770. [CrossRef]

13. Parida, S.; Sharma, D. The power of small changes: Comprehensive analyses of microbial dysbiosis in breast cancer. Biochim. Biophys. Acta Rev. Cancer 2019, 1871, 392-405. [CrossRef]

14. Scott, T.A.; Quintaneiro, L.M.; Norvaisas, P.; Lui, P.P.; Wilson, M.P.; Leung, K.Y.; Herrera-Dominguez, L.; Sudiwala, S.; Pessia, A.; Clayton, P.T.; et al. Host-microbe co-metabolism dictates cancer drug efficacy in C. elegans. Cell 2017, 169, 442-456. [CrossRef]

15. Gonzalez-Sarrias, A.; Tome-Carneiro, J.; Bellesia, A.; Tomas-Barberan, F.A.; Espin, J.C. The ellagic acid-derived gut microbiota metabolite, urolithin A, potentiates the anticancer effects of 5-fluorouracil chemotherapy on human colon cancer cells. Food Funct. 2015, 6, 1460-1469. [CrossRef]

16. Liu, J.; Liu, C.; Yue, J. Radiotherapy and the gut microbiome: Facts and fiction. Radiat. Oncol. 2021, 16, 9. [CrossRef] [PubMed]

17. Yu, T.; Guo, F.; Yu, Y.; Sun, T.; Ma, D.; Han, J.; Qian, Y.; Kryczek, I.; Sun, D.; Nagarsheth, N.; et al. Fusobacterium nucleatum promotes chemoresistance to colorectal cancer by modulating autophagy. Cell 2017, 170, 548-563.E16. [CrossRef] [PubMed]

18. Roy, S.; Trinchieri, G. Microbiota: A key orchestrator of cancer therapy. Nat. Rev. Cancer 2017, 17, 271-285. [CrossRef]

19. Ohara, T.; Suzutani, T. Intake of Bifidobacterium longum (BB536) and Fructo-Oligosaccharides (FOS) prevents colorectal carcinogenesis. Euroasian J. Hepatogastroenterol. 2018, 8, 11-17. [CrossRef]

20. Ross, K. Gut microbial short chain fatty acids are associated with pathological complete response (pCR) after neoadjuvant chemotherapy for breast cancer. In Proceedings of the 12th European Breast Cancer Conference, Virtual Conference, 2-3 October 2020.

21. Coutzac, C.; Jouniaux, J.M.; Paci, A.; Schmidt, J.; Mallardo, D.; Seck, A.; Asvatourian, V.; Cassard, L.; Saulnier, P.; Lacroix, L.; et al. Systemic short chain fatty acids limit antitumor effect of CTLA-4 blockade in hosts with cancer. Nat. Commun. 2020, 11, 2168. [CrossRef] [PubMed]

22. Yoshioka, N.; Taniguchi, Y.; Yoshida, A.; Nakata, K.; Nishizawa, T.; Inagawa, H.; Kohchi, C.; Soma, G. Intestinal macrophages involved in the homeostasis of the intestine have the potential for responding to LPS. Anticancer Res. 2009, 29, 4861-4865.

23. Childs, A.; Mehta, D.; Gerner, E. Polyamine-dependent gene expression. Cell. Mol. Life Sci. 2003, 60, 1394-1406. [CrossRef] 
24. Nakayama, Y.; Torigoe, T.; Minagawa, N.; Yamaguchi, K. The clinical usefulness of urinary N(1), N(12)-diacetylspermine (DiAcSpm) levels as a tumor marker in patients with colorectal cancer. Oncol. Lett. 2012, 3, 970-974. [CrossRef]

25. Human Microbiome Project Consortium. Structure, function and diversity of the healthy human microbiome. Nature 2012, 486, 207-214. [CrossRef]

26. Qin, J.; Li, R.; Raes, J.; Arumugam, M.; Burgdorf, K.S.; Manichanh, C.; Nielsen, T.; Pons, N.; Levenez, F.; MetaHIT Consortium; et al. A human gut microbial gene catalogue established by metagenomic sequencing. Nature 2010, 464, 59-65. [CrossRef]

27. Garrett, W.S. Cancer and the microbiota. Science 2015, 348, 80-86. [CrossRef] [PubMed]

28. Drewes, J.L.; Housseau, F.; Sears, C.L. Sporadic colorectal cancer: Microbial contributors to disease prevention, development and therapy. Br. J. Cancer 2016, 115, 273-280. [CrossRef] [PubMed]

29. Taghinezhad-S, S.; Mohseni, A.H.; Fu, X. Intervention on gut microbiota may change the strategy for management of colorectal cancer. J. Gastroenterol. Hepatol. 2020, 36, 1508-1517. [CrossRef] [PubMed]

30. Gopalakrishnan, V.; Spencer, C.N.; Nezi, L.; Reuben, A.; Andrews, M.C.; Karpinets, T.V.; Prieto, P.A.; Vicente, D.; Hoffman, K.; Wei, S.C.; et al. Gut microbiome modulates response to anti-PD-1 immunotherapy in melanoma patients. Science 2018, 359, 97-103. [CrossRef]

31. Heshiki, Y.; Vazquez-Uribe, R.; Li, J.; Ni, Y.; Quainoo, S.; Imamovic, L.; Li, J.; Sørensen, M.; Chow, B.K.C.; Weiss, G.J.; et al. Predictable modulation of cancer treatment outcomes by the gut microbiota. Microbiome 2020, 8, 28. [CrossRef]

32. Chen, W.; Liu, F.; Ling, Z.; Tong, X.; Xiang, C. Human intestinal lumen and mucosa-associated microbiota in patients with colorectal cancer. PLoS ONE 2012, 7, e39743. [CrossRef] [PubMed]

33. Saffarian, A.; Mulet, C.; Regnault, B.; Amiot, A.; Tran-Van-Nhieu, J.; Ravel, J.; Sobhani, I.; Sansonetti, P.J.; Pédron, T. Cryptand mucosa-associated core microbiotas in humans and their alteration in colon cancer patients. mBio 2019, 10, e1315-e1319. [CrossRef] [PubMed]

34. Gao, Z.; Guo, B.; Gao, R.; Zhu, Q.; Qin, H. Microbiota disbiosis is associated with colorectal cancer. Front. Microbiol. 2015, 6, 20. [CrossRef] [PubMed]

35. Yan, X.; Liu, L.; Li, H.; Qin, H.; Sun, Z. Clinical significance of Fusobacterium nucleatum, epithelial-mesenchymal transition, and cancer stem cell markers in stage III/IV colorectal cancer patients. OncoTargets Ther. 2017, 10, 5031-5046. [CrossRef]

36. Gevers, D.; Kugathasan, S.; Denson, L.A.; Vázquez-Baeza, Y.; Van Treuren, W.; Ren, B.; Schwager, E.; Knights, D.; Song, S.J.; Yassour, M.; et al. The treatment-naive microbiome in new-onset Crohn's disease. Cell Host Microbe 2014, 15, 382-392. [CrossRef]

37. Wu, N.; Yang, X.; Zhang, R.; Li, J.; Xiao, X.; Hu, Y.; Chen, Y.; Yang, F.; Lu, N.; Wang, Z.; et al. Dysbiosis signature of fecal microbiota in colorectal cancer patients. Microb. Ecol. 2013, 66, 462-470. [CrossRef]

38. Bao, Y.; Tang, J.; Qian, Y.; Sun, T.; Chen, H.; Chen, Z.; Sun, D.; Zhong, M.; Chen, H.; Hong, J.; et al. Long noncoding RNA BFAL1 mediates enterotoxigenic Bacteroides fragilis-related carcinogenesis in colorectal cancer via the RHEB/mTOR pathway. Cell Death Dis. 2019, 10, 675. [CrossRef] [PubMed]

39. Hsu, R.Y.; Chan, C.H.; Spicer, J.D.; Rousseau, M.C.; Giannias, B.; Rousseau, S.; Ferri, L.E. LPS-induced TLR4 signaling in human colorectal cancer cells increases beta1 integrin-mediated cell adhesion and liver metastasis. Cancer Res. 2011, 71, 1989-1998. [CrossRef]

40. Murff, H.J.; Shu, X.O.; Li, H.; Dai, Q.; Kallianpur, A.; Yang, G.; Cai, H.; Wen, W.; Gao, Y.T.; Zheng, W. A prospective study of dietary polyunsaturated fatty acids and colorectal cancer risk in Chinese women. Cancer Epidemiol. Biomark. Prev. 2009, 18, 2283-2291. [CrossRef]

41. Wang, D.; Mann, J.R.; DuBois, R.N. The role of prostaglandins and other eicosanoids in the gastrointestinal tract. Gastroenterology 2005, 128, 1445-1461. [CrossRef]

42. Bansal, A.; Simon, M.C. Glutathione metabolism in cancer progression and treatment resistance. J. Cell Biol. 2018, 217, 2291-2298. [CrossRef] [PubMed]

43. Lu, S.C. Regulation of glutathione synthesis. Mol. Asp. Med. 2009, 30, 42-59. [CrossRef] [PubMed]

44. Coffelt, S.B.; Wellenstein, M.D.; de Visser, K.E. Neutrophils in cancer: Neutral no more. Nat. Rev. Cancer 2016, 16, 431-446. [CrossRef]

45. Thomas, A.M.; Manghi, P.; Asnicar, F.; Pasolli, E.; Armanini, F.; Zolfo, M.; Beghini, F.; Manara, S.; Karcher, N.; Pozzi, C.; et al. Metagenomic analysis of colorectal cancer datasets identifies cross-cohort microbial diagnostic signatures and a enlace with choline degradation. Nat. Med. 2019, 25, 667-678. [CrossRef] [PubMed]

46. Noack, J.; Dongowski, G.; Hartmann, L.; Blaut, M. The human gut bacteria Bacteroides thetaiotaomicron and Fusobacterium varium produce putrescine and spermidine in cecum of pectin-fed gnotobiotic rats. J. Nutr. 2000, 130, 1225-1231. [CrossRef]

47. Goodwin, A.C.; Destefano Shields, C.E.; Wu, S.; Huso, D.L.; Wu, X.; Murray-Stewart, T.R.; Hacker-Prietz, A.; Rabizadeh, S.; Woster, P.M.; Sears, C.L.; et al. Polyamine catabolism contributes to enterotoxigenic Bacteroides fragilis-induced colon tumorigenesis. Proc. Natl. Acad. Sci. USA 2011, 108, 15354-15359. [CrossRef]

48. Johnson, C.H.; Dejea, C.M.; Edler, D.; Hoang, L.T.; Santidrian, A.F.; Felding, B.H.; Ivanisevic, J.; Cho, K.; Wick, E.C.; Hechenbleikner, E.M.; et al. Metabolism links bacterial biofilms and colon carcinogenesis. Cell Metab. 2015, 21, 891-897. [CrossRef]

49. Mendez, R.; Kesh, K.; Arora, N.; Di Martino, L.; McAllister, F.; Merchant, N.; Banerjee, S.; Banerjee, S. Microbial dysbiosis and polyamine metabolism as predictive markers for early detection of pancreatic cancer. Carcinogenesis 2020, 41, 561-570. [CrossRef] [PubMed] 
50. Arruabarrena-Aristorena, A.; Zabala-Letona, A.; Carracedo, A. Oil for the cancer engine: The cross-talk between oncogenic signaling and polyamine metabolism. Sci. Adv. 2018, 4, eaar2606. [CrossRef]

51. Bhat, M.I.; Kapila, R. Dietary metabolites derived from gut microbiota: Critical modulators of epigenetic changes in mammals. Nutr. Rev. 2017, 75, 374-389. [CrossRef]

52. Jahani-Sherafat, S.; Alebouyeh, M.; Moghim, S.; Amoli, H.A.; Safaei, H.G. Role of gut microbiota in the pathogenesis of colorectal cancer; a review article. Gastroenterol. Hepatol. Bed Bench. 2018, 11, 101-109.

53. Sokol, H.; Seksik, P.; Furet, J.P.; Firmesse, O.; Nion-Larmurier, I.; Beaugerie, L.; Cosnes, J.; Corthier, G.; Marteau, P.; Doré., J. Low counts of Faecalibacterium prausnitzii in colitis microbiota. Inflamm. Bowel Dis. 2009, 15, 1183-1189. [CrossRef]

54. Lopez-Siles, M.; Martinez-Medina, M.; Abellà, C.; Busquets, D.; Sabat-Mir, M.; Duncan, S.H.; Aldeguer, X.; Flint, H.J.; Garcia-Gil, L.J. Mucosa-associated Faecalibacterium prausnitzii phylotype richness is reduced in patients with inflammatory bowel disease. Appl. Environ. Microb. 2015, 81, 7584-7592. [CrossRef]

55. Rios-Covian, D.; Gueimonde, M.; Duncan, S.H.; Flint, H.J.; de los Reyes-Gavilan, C.G. Enhanced butyrate formation by crossfeeding between Faecalibacterium prausnitzii and Bifidobacterium adolescentis. FEMS Microbiol. Lett. 2015, 362 , fnv176. [CrossRef]

56. Singh, N.; Gurav, A.; Sivaprakasam, S.; Brady, E.; Padia, R.; Shi, H.; Thangaraju, M.; Prasad, P.D.; Manicassamy, S.; Munn, D.H.; et al. Activation of Gpr109a, receptor for niacin and the commensal metabolite butyrate, suppresses colonic inflammation and carcinogenesis. Immunity 2014, 40, 128-139. [CrossRef]

57. Salcedo, R.; Worschech, A.; Cardone, M.; Jones, Y.; Gyulai, Z.; Dai, R.M.; Wang, E.; Ma, W.; Haines, D.; O’hUigin, C.; et al. MyD88-mediated signaling prevents development of adenocarcinomas of the colon: Role of interleukin 18. J. Exp. Med. 2010, 207, 1625-1636. [CrossRef]

58. Vaishnava, S.; Behrendt, C.L.; Ismail, A.S.; Eckmann, L.; Hooper, L.V. Paneth cells directly sense gut commensals and maintain homeostasis at the intestinal host-microbial interface. Proc. Natl. Acad. Sci. USA 2008, 105, 20858-20863. [CrossRef] [PubMed]

59. Van Immerseel, F.; De Buck, J.; Boyen, F.; Bohez, L.; Pasmans, F.; Volf, J.; Sevcik, M.; Rychlik, I.; Haesebrouck, F.; Ducatelle, R. Medium-chain fatty acids decrease colonization and invasion through hilA suppression shortly after infection of chickens with Salmonella enterica serovar Enteritidis. Appl. Environ. Microbiol. 2004, 70, 3582-3587. [CrossRef]

60. Sturgeon, C.; Fasano, A. Zonulin, a regulator of epithelial and endothelial barrier functions, and its involvement in chronic inflammatory diseases. Tissue Barriers 2016, 4, e1251384. [CrossRef] [PubMed]

61. Wright, D.P.; Rosendale, D.; Roberton, A.M. Prevotella enzymes involved in mucin oligosaccharide degradation and evidence for a small operon of genes expressed during growth on mucin. FEMS Microbiol. Lett. 2000, 190, 73-79. [CrossRef] [PubMed]

62. Mandard, A.M.; Dalibard, F.; Mandard, J.C.; Marnay, J.; Henry-Amar, M.; Petiot, J.F.; Roussel, A.; Jacob, J.H.; Segol, P.; Samama, G. Pathologic assessment of tumor regression after preoperative chemoradiotherapy of esophageal carcinoma. Clinicopathologic correlations. Cancer 1994, 73, 2680-2686. [CrossRef]

63. Ribeiro, W.R.; Vinolo, M.A.R.; Calixto, L.A.; Ferreira, C.M. Use of gas chromatography to quantify short chain fatty acids in the serum, colonic luminal content and feces of mice. Bio-Protocol 2018, 8, e3089. [CrossRef]

64. Mendes, E.; Acetturi, B.G.; Thomas, A.M.; Martins, F.; Crisma, A.R.; Murata, G.; Braga, T.T.; Camâra, N.; Franco, A.; Setubal, J.C.; et al. Prophylactic supplementation of Bifidobacterium longum 51A protects mice from ovariectomy-induced exacerbated allergic airway inflammation and airway hyperresponsiveness. Front. Microbiol. 2017, 8, 1732. [CrossRef] [PubMed]

65. Fellows, R.; Denizot, J.; Stellato, C.; Cuomo, A.; Jain, P.; Stoyanova, E.; Balázsi, S.; Hajnády, Z.; Liebert, A.; Kazakevych, J.; et al. Microbiota derived short chain fatty acids promote histone crotonylation in the colon through histone deacetylases. Nat. Commun. 2018, 9, 105. [CrossRef]

66. Liang, J. A sensitive method for the quantification of short-chain fatty acids by benzyl chloroformate derivatization combined with GC-MS. Analyst 2020, 145, 2692-2700. [CrossRef]

67. Samarra, I.; Ramos-Molina, B.; Queipo-Ortuño, M.I.; Tinahones, F.J.; Arola, L.; Delpino-Rius, A.; Herrero, P.; Canela, N. Genderrelated differences on polyamine metabolome in liquid biopsies by a simple and sensitive two-step liquid-liquid extraction and LC-MS/MS. Biomolecules 2019, 9, 779. [CrossRef] 